\title{
Análisis y desarrollo de la educación contable: temáticas de su abordaje y principales problemáticas según el pensamiento estudiantil socializado por la Fenecop $(2000-2016)^{*}$
}

\author{
Analysis and Development of the Accounting Education: Themes to be Approached and Main Problems according \\ to the Student's Thinking Disseminated by Fenecop (2000-2016) \\ Análise e desenvolvimento da educação contábil: temáticas da sua abordagem e principais problemáticas segundo o \\ pensamento estudantil socializado pela Fenecop (2000-2016)
}

Driver Ferney Ramirez Henao ${ }^{\text {a }}$

DOI: https://doi.org/10.11144/Javeriana.cc18-46.adec

Universidad del Valle, Colombia

driver.ramirez@correounivalle.edu.co

ORCID: http://orcid.org/0000-0002-9092-6362

Fecha de recepción: 21 Abril 2017

Fecha de aprobación: 15 Junio 2017

Fecha de publicación: 15 Diciembre 2017

\section{Resumen:}

Este trabajo analiza las problemáticas de la educación contable que han sido sustentadas por estudiantes mediante las ponencias que presentaron, desde el año 2000 hasta el 2016, en las comisiones educativas de los congresos nacionales organizadas en torno a la materia; jornadas que realizan conjuntamente las organizaciones estudiantiles de cada programa académico y/o facultad de Contaduría Pública en Colombia, bajo la tutela de la Federación Nacional de Estudiantes de Contaduría Pública (Fenecop). Esta federación surge en 1988, y desde entonces ha impulsado el encuentro y la organización estudiantil en torno a la disciplina. En el presente estudio se realiza un análisis de contenido a las ponencias de la comisión educativa, con lo cual se busca develar el sentido de las problemáticas que atañen a la educación contable. El examen de las veintitrés ponencias revisadas abarca (a) el estudio de las temáticas idóneas para el abordaje de la educación contable y (b) el análisis de problemas concretos de la educación contable. Ambos criterios son interpretados de acuerdo con un marco de referencia compuesto por el movimiento estudiantil contable, la modernización de Colombia y el condicionamiento de la Contabilidad. Al final del estudio se observa que los estudiantes no consideran que el análisis educativo se limite a ser un tema exclusivo del currículo, y pantean cómo los problemas identificados denuncian múltiples factores que corresponden a cuatro puntos de encuentro: el contexto, el currículo, la enseñanza y la pedagogía. Código JEL: M41, M49

Palabras clave: Educación contable, análisis de contenido, Fenecop, modernización, condicionamiento.

\section{Abstract:}

This work examines the problems in the accounting education that have been raised by students with their presentations from 2000 to 2016, in the student's commissions created in the national congresses dealing with this subject-matter. These events are carried out partneting with student's associations from every Public Accountancy program and/or faculty in Colombia, under the direction of the National Federation of Public Accounting Students (Fenecop). This federation was founded in 1988. Since then it has promoted that students gather and organize around this discipline. This study consists in a content analysis of the presentations made in those student's commissions. The aim is to disclose the sense of the problems concerning the accounting education. The examination to the 23 presentations considered herein includes: (a) to study which themes/topics are relevant when approaching the accounting education; (b) to analyze specific problems in the accounting education. Both criteria are construed according to a benchmark provided by the accounting student movement, the modernization of Colombia and the conditionings to the acounting. At the end, it can be observed that students do not think that the educative analysis is constrained to an exclusive curricular theme. Instead, they state that the identified problems make known multiple factors corresponding to four converging points: context, curriculum, teaching, and pedagogy.

Keywords: accounting education, content analysis, Fenecop, modernization, conditioning.

Notas de autor

a Autor de correspondencia. Correo electrónico: driver.ramirez@correounivalle.edu.co 


\section{Resumo:}

Este trabalho analisa as problemáticas da educação contábil expostas por estudantes mediante palestra apresentada desde o ano 2000 até 2016, nas comissões educacionais dos congressos nacionais organizadas em torno do assunto; jornadas que realizam conjuntamente as organizações estudantis de cada programa académico e/ou faculdade de Contabilidade Pública na Colômbia, sob a tutela da Federação Nacional de Estudantes de Contabilidade Pública (Fenecop). A federação surge em 1988 e desde então impulsiona o encontro e a organização estudantil em torno da disciplina. No presente estudo é realizada análise de conteúdo das palestras da comissão educacional, com o qual se visa desvendar o sentido das problemáticas que dizem respeito à educação contábil. A observação das vinte e três palestras revistas cobre (a) o estudo das temáticas idóneas para a abordagem da educação contábil e (b) a análise de problemas concretos da educação contábil. Ambos os critérios são interpretados de acordo a um quadro de referencia composto pelo movimento estudantil contábil, a modernização de Colômbia e o condicionamento da Contabilidade. No final do estudo observa-se que os estudantes não acham que a análise educativa seja limitada a um tema exclusivo do currículo e mostram como os problemas identificados denunciam múltiplos fatores correspondentes a quatro pontos de encontro: contexto, currículo, ensino e pedagogia.

Palavras-chave: Educação contábil, análise de conteúdo, Fenecop, modernização, condicionamento.

\section{Introducción}

Este artículo busca otorgar sentido a las problemáticas de educación contable que la comunidad estudiantil de Contaduría Pública ha manifestado por medio de ponencias en los últimos catorce congresos nacionales que han sido organizados en torno a la disciplina. Dichas jornadas son realizadas conjuntamente por las organizaciones estudiantiles de cada programa académico y/o facultad de Contaduría Pública en Colombia, con el tutelaje de la Federación Nacional de Estudiantes de Contaduría Pública (Fenecop). ${ }^{1}$

La Fenecop surge como organización en 1988 (Sarmiento y Muñoz, 2011). Según estatutos generales, se identifica por su carácter nacionalista, autónomo, amplio, democrático y popular, tanto en el sector estudiantil como en el profesional. ${ }^{2}$ Su finalidad se enmarca en cuatro aspectos: (a) el investigativo, que se relaciona con la promoción de una teoría contable científica, humanista y con proyección social; (b) el organizativo, el cual supone impulsar el encuentro y la organización estudiantil; (c) el politico-económico, que envuelve la lucha por una legislación contable organizada en consonancia con la realidad del país, y que defiende la soberanía nacional y los derechos humanos; y (d) el sociocultural, el cual apunta hacia la defensa de los valores culturales, éticos y morales de la profesión y de los colombianos. En concordancia, la Fenecop se ha organizado en cinco comisiones, con el fin de abarcar las principales preocupaciones estudiantiles sobre temas del saber contable: la comisión político-organizativa, la normativo-técnica, la educativa, la socioambiental y la de pensamiento contable. $^{3}$

Concretamente, la comisión educativa se ha caracterizado por su capacidad de concertar discusiones determinantes para la trayectoria académica y política de la Fenecop. El primer congreso nacional, que fue realizado en 1984 en la ciudad de Armenia, estableció dos comisiones: una encargada de estudiar la educación contable, y otra con el objetivo de evaluar el reglamento profesional y la técnica contable. Así pues, es pertinente sostener que la preocupación por la educación contable ha estado presente desde los primeros encuentros estudiantiles, lo cual sitúa a esta comisión en un contexto histórico de problematización permanente.

Con todo, en sus ponencias los estudiantes no abordan el tema educativo per se, sino que su aproximación a tal temática viene acompañada regularmente de un acercamiento contextual a la educación contable. En ese escenario, es posible afirmar que la preocupación estudiantil por la educación contable también ha involucrado un marcado interés por la sociedad, la economía y la política. Ese deseo de observar ampliamente la educación contable obedece a los momentos históricos que dieron lugar al movimiento popular estudiantil de la contaduría pública en Colombia. De este modo, la naturaleza y los fines de la Fenecop se definieron en los marcos del movimiento popular estudiantil y del gremio profesional nacionalista, cuyo proyecto tiene 
claras pretensiones políticas y en su momento fue "contagiado [...] por el auge de las izquierdas" (Gómez y Ospina, 2009, p. 20).

Según lo anterior, los preceptos de la Fenecop se gestaron al calor de reivindicaciones estudiantiles y profesionales que exigían autonomía y soberanía como valores fundantes. En consonancia, dichas máximas se sitúan por encima de la arbitrariedad y el aperturismo con los que el capitalismo y el neoliberalismo fueron establecidos socialmente en Colombia.

Así, las ponencias estudiantiles evocan esa necesidad de confrontar y de pensar críticamente los elementos que movilizan a la educación contable, en medio de la realidad económica, política y social de Colombia. Dado que las ponencias buscan comprender lo educativo a partir de una lectura contextual, el abordaje analítico que se presenta en este artículo reconoce dicha orientación como su rasgo esencial. Ante la complejidad que caracteriza a las ponencias, este artículo se concentra en el sentido que se le puede otorgar a los aspectos que la comunidad estudiantil ha problematizado a lo largo del tiempo. En consecuencia, resultó necesario reconocer los diversos caminos y las múltiples posibilidades temáticas; factores esenciales para el abordaje de la educación contable. Asimismo, también fue fundamental identificar los problemas concretos de tal esfera educativa.

Por lo anterior, en este artículo se analizan las ponencias que fueron publicadas en la comisión educativa desde la versión XIV (2000) hasta la edición XXVII (2016) de dichos congresos nacionales. Además, el estudio se organiza con base en el trabajo Texto, testimonio y metatexto: el análisis de contenido en la investigación en educación del profesor Alexander Ruíz Silva (2006); investigación en la que se hace una caracterización del análisis de contenido a partir de la búsqueda del sentido de los textos.

Asimismo, cabe mencionar el trabajo del profesor William Rojas (2001), dado que este constituye una aproximación previa al ejercicio de sistematización y análisis que se presentará a continuación. Cabe anotar de igual modo que, como parte de su estudio, Rojas (2001) coordinó académicamente a un grupo de estudiantes para que fuera posible revisar las ponencias publicadas en todas las comisiones de los congresos nacionales sujetos a su estudio, los cuales iban desde el año 1984 hasta el $2000 .^{4}$

En consecuencia, el análisis de las ponencias se desarrolla en dos momentos de acuerdo con nociones divergentes del sentido según lo amerita la materia: (a) el estudio de las temáticas pertinentes para el abordaje de la educación contable, y (b) el análisis de los problemas de la educación contable. Asimismo, como parte ineludible de esta búsqueda, se analizan los contenidos y los problemas educativos con base en un marco de referencia dividido de la forma a continuación descrita.

En primer lugar, se presentan los elementos históricos que permiten contemplar el momento en el cual la movilización popular estudiantil contable se adhiere al gremio profesional nacionalista de la Contaduría Pública; una anexión que se produjo con el fin de implementar una estrategia académica dirigida hacia el mejoramiento de las condiciones de la disciplina y de la profesión contable, y que también procuró tener repercusiones positivas en el país. En segundo lugar, se explica en qué consistió la modernización del Estado colombiano, pues este proceso fundó las bases del posterior desarrollo capitalista y neoliberal del país. Finalmente, se exponen los papeles que juegan la contabilidad y la educación contable en el contexto de modernización que se aborda en el presente estudio; una aproximación que permite reconocer qué tipo de condicionamientos establecen ambos aspectos en su entorno.

Los tres puntos que han sido listados anteriormente son formulados en acápites distintos y conforman el marco de referencia que permite postular y comprender el sentido correspondiente a los trabajos estudiantiles. En seguida, se analizan las ponencias de acuerdo con dos aspectos que constituyen ópticas idóneas para abordar el análisis: las temáticas propicias para pensar la educación contable, y las problemáticas que han sido señaladas en las ponencias. Este proceso de revisión y de categorización de la información se formula de modo emergente, lo cual quiere decir que las categorías analíticas se organizan de acuerdo con el estudio mismo de las ponencias. Como cierre del estudio, se articulan las categorías analíticas observadas en las ponencias con el marco de referencia tratado. 


\section{Movimiento estudiantil contable: fragmentos históricos de una estrategia académica}

A lo largo de su estudio, Mauricio Achila (2012) caracteriza los periodos históricos de las movilizaciones estudiantiles en Colombia según categorías a las cuales corresponden periodos y rasgos bien definidos. En tales términos, se refiere a los Primeros Pasos (1909-1929); a la Visibilidad Oscilante (1930-1945); a la Resistencia Democrática (1946-1957); a la Radicalización contra el Bipartidismo (1958-1974); a la etapa dirigida hacia el Movimiento Popular (1975-1990), y a la Crisis y Recomposición (1991-2011).

De acuerdo con lo anterior, el gremio estudiantil contable tuvo su origen en el marco de la etapa abocada hacia el Movimiento Popular (1975-1990). En tal escenario, las exigencias planteadas buscaron contrarrestar el emprendimiento estatal, mientras favorecían el modelo económico neoliberal y sus políticas de apertura económica. A modo de réplica, la movilización estudiantil de aquel momento se caracterizó por la necesidad de manifestar determinadas asociaciones con las 'clases populares'; empalmes que estaban compuestos de ciertos vínculos con sectores rurales, estudiantiles y de trabajadores (Achila, 2012).

En tanto, las mismas causas contextuales que posibilitaron la apertura económica, las cuales generaron la manifestación popular de los estudiantes de Contaduría Pública, fueron problematizadas desde 1930 por contadores públicos y por asociaciones profesionales organizadas en torno a la disciplina. Esa reivindicación profesional contable sostenía que el aperturismo económico iniciado en Colombia a comienzos del siglo XX había afectado la soberanía nacional, pues permitía el ingreso de firmas multinacionales al país; un fenómeno que ocasionó la concentración del mercado de servicios contables (Gracia, 1991). En consecuencia, el sector de la profesión contable que se pronunció en contra de las firmas multinacionales fue conocido como el nacionalista, mientras que el gremio profesional que auspiciaba la entrada de dichas firmas al país fue conocido como el universalista (Millán, 1975).

Ante tal dicotomía, los estudiantes de Contaduría Pública que expresaron en la década de 1970 su inconformidad con el planteamiento neoliberal del Estado, se adhirieron a la movilización social gestada por el sector nacionalista. De ese modo, la comunidad estudiantil contable forjó sus referencias ideológicas y políticas de acuerdo con dos perspectivas: la que asumió como gremio estudiantil, y la que adoptó por cuenta de la discusión profesional de contadores públicos a propósito del auge de las firmas multinacionales. Los dos ambientes de confrontación —el estudiantil y el profesional - constituyen la base que permite entender el componente reflexivo y crítico que los estudiantes han privilegiado en la Fenecop; aspecto que se evidencia en la defensa política y académica que ellos hacen de sus propias ideas en los congresos nacionales.

Durante las primeras reuniones estudiantiles de la profesión contable que tenían carácter federativo - los congresos nacionales de 1984 y 1988-, los estudiantes reconocieron un ambiente desalentador en términos profesionales, sociales y económicos; un entorno ante el cual era necesario formular una estrategia académica que pensara en alternativas centradas en la investigación: posturas según las cuales fuera posible proponer un mejor devenir para el país, la profesión y la disciplina contable (Sarmiento y Muñoz, 2011). A ello respondió el ulterior desarrollo de dichas jornadas.

En lo corrido de los congresos nacionales, los estudiantes han sugerido de forma reflexiva y crítica múltiples alternativas viables ante las prácticas dominantes de su disciplina; propuestas que configuran nuevos esquemas para el desarrollo del país y de la materia. Así, en lo que tiene que ver con la educación contable, dado que esta temática ha sido omnipresente en la historia de la Fenecop, los estudiantes han alcanzado un vasto nivel de estudio y han evidenciado que tienen grandes capacidades para su problematización. Además, la comunidad estudiantil ha analizado a profundidad la educación contable, lo cual le ha permitido establecer una relación inseparable entre la dinámica educativa y los fenómenos sociales, económicos e históricos propios del contexto. 
En síntesis, los estudiantes que han atendido de forma escrita (vía ponencias) el llamado de la Fenecop, aún conservan las referencias ideológicas y políticas del gremio estudiantil popular y del sector profesional nacionalista. Para estos estudiantes, la disciplina y la profesión contable comparten una tensión estructural robustecida por la puesta en marcha del ordenamiento capitalista y el modelo económico neoliberal en Colombia. Según las indagaciones estudiantiles, a la educación contable también le son transferidos los antagonismos estructurales de la disciplina y la profesión, pues el aludido es un campo permeado por la lógica que surge desde el ángulo capitalista y neoliberal. Asimismo, los estudiantes proponen una concepción diferente de su propia educación; una noción según la cual les sea posible hacer visibles sus conflictos y lograr su transformación: ante esta necesidad de cambio, los mismos estudiantes perciben que la enseñanza de la contabilidad ha sido estática y que mantiene un carácter de objetividad y neutralidad apabullante (Rojas, 2009), lo cual desestimula un modelo de enseñanza diferente, que vea en ella un área de investigación e indagación sociohistórica (Gil, 2010; Ospina, 2006).

\section{Modernización estatal: capitalismo y neoliberalismo en Colombia}

Este trabajo arguye que la modernización de la estructura estatal colombiana fue la principal causa de la manifestación estudiantil y profesional de la Contaduría Pública, especialmente ante la adopción del ordenamiento capitalista y la implementación del modelo económico y político neoliberal. En ese sentido, el profesor Fernando Cruz (2016) ilustra la diferencia existente entre modernidad y modernización, y lúcidamente señala el papel de Colombia en este proceso:

la modernidad es una mentalidad que se expresa en el modo de pensar y de vivir. La modernización, por el contrario, es un concepto que se refiere, ante todo, a la incorporación de nuevas tecnologías y procedimientos para mejorar la eficiencia y la productividad en los procesos de producción, infraestructura y prestación de servicios. Desde este punto de vista, en Colombia, [...] es evidente que se confunde lo uno con lo otro. Con lo cual se escamotea muy fácilmente cualquier proyecto serio de modernidad mental, a manos de políticas de modernización [...]. Como quien dice: modernización en el aparato productivo y en los procedimientos, y premodernidad cultural y mental en las cabezas. (p. 47)

En ese contexto, desde las primeras décadas del siglo XX, el Gobierno ha buscado los caminos idóneos para superar la república "pastoril y agraria" (Méndez, 1988, p. 138) de la Colombia premoderna. Cabe anotar que las reformas socioeconómicas y las misiones internacionales de comienzos del siglo pasado le abrieron paso al cometido fundacional de un Estado moderno. En ese escenario, los debates entre proteccionistas (que abogaban por la mayor intervención del Estado) y los aperturistas (que defendían la libertad del mercado) eran cada vez mayores, hasta que, hacia 1920, el ingreso de la economía colombiana en el mercado global se transformó en un hecho; y algunas estructuras institucionales surgieron como resultado de la misión Kemmerer: el Banco de la República, la Superintendencia Bancaria, la Contraloría General, entre otras (Córdoba, 2014; Santos, 2017).

Se podría pensar que, en paralelo al cambio de enfoques que supone el paso de un modelo económico cerrado a uno abierto, el Estado colombiano debió liderar también un cambio (o una transformación) cultural y mental de la sociedad. Sin embargo, los hechos no obedecieron ese orden de ideas.

Según Rodolfo Méndez (1988), las políticas impulsadas por el Gobierno colombiano para superar la mentada república pastoril y agraria del siglo XIX, buscaron consolidar una base sobre la cual se edificarán principalmente los elementos del capitalismo. Una vez se considera lo anterior, y en sintonía con el aporte del profesor Cruz (2016), es posible añadir que las actividades encaminadas por el país hacia el ingreso a la modernidad priorizaron los aspectos económicos, políticos, científicos y técnicos del proyecto moderno, y desatendieron parte esencial de sus dimensiones filosóficas, artísticas e ideológicas.

Ante ese escenario, cabe reiterar que en Colombia el proceso de renovación estatal se materializó a partir de políticas de modernización organizadas con el fin de configurar el funcionamiento capitalista de la economía 
y de la sociedad. De acuerdo con Cruz $(1998,2016)$, para que Colombia hubiese alcanzado un proyecto serio de modernidad mental, hubiese sido necesario acompañar el interés económico, político, científico y técnico, de avances en materia de pensamiento (su naturaleza filosófica), creatividad (su naturaleza artística) y de fraternidad, solidaridad, igualdad y libertad (su naturaleza ideológica).

Ahora bien, el capitalismo que se introdujo en la modernización del Estado colombiano tiene un cierto espiritu, una determinada intención que le otorga sentido al proceso económico y social que lo acompaña. En suma, el capitalismo incorporado al país no buscaba solamente acumular capitales, sino que esperaba también reproducir capital con base en la misma dinámica de acumulación; en palabras de Weber (2009), se trata del espíritu del capitalismo moderno, que se basa en la reproducción del capital por el capital mismo (p. 73). Este espíritu capitalista opera con base en un arreglo ético de individuación (Boyce, 2008; Cruz, 1998, 2016), forjado por medio de la relación que se teje entre la empresa, el sujeto y el Estado: actor último que considera moralmente legítima la aspiración por la acumulación (Sombart, 1979; Weber, 2009).

En tal contexto, dado que los ánimos de modernización en Colombia profundizaron en los asuntos económicos, políticos, científicos y técnicos, sin detenerse en lo filosófico, artístico e ideológico, el arreglo ético de individuación (Boyce, 2008; Cruz, 1998, 2016) y el espiritu capitalista (Weber, 2009) se interiorizaron en la sociedad colombiana. En consecuencia, se dio cabida a una realidad social en la cual predominan los criterios instrumentales y funcionales que contribuyen con el mantenimiento (o legitimación) del capitalismo.

Una vez fueron determinados los lineamientos institucionales capitalistas que se proponían impulsar a la sociedad y la economía colombiana, en la década de 1980 acaeció el despliegue del modelo neoliberal, que se perfiló como un proyecto político y económico que contaba con la capacidad de gestionar asuntos culturales, sociales, educativos, medioambientales y éticos, entre otros (Chiapello, 2017; Puello-Socarrás, 2008). Asimismo, el modelo neoliberal liga la actividad del país con el comportamiento de la política económica mundial, porque asume que el mercado administra los recursos de una forma óptima (Chiapello, 2017; Puello-Socarrás, 2008).

Un ejemplo de actividad económica auspiciada por el modelo neoliberal es la minería a cielo abierto. Perteneciente a la compañía Anglo Gold Ashanti, La Colosa es un proyecto minero impulsado desde 2007 por grandes grupos económicos avalados por el Gobierno; una iniciativa que ha tenido importantes repercusiones sociales y ambientales. Al respecto, Lombardo Paredes, vicepresidente de la multinacional minera Gran Colombia Gold, afirma "que la minería a cielo abierto en Colombia es inviable, debido al impacto ambiental y social que genera por el uso de químicos y tóxicos, las dimensiones de terreno que afecta y los desechos contaminantes" (Caracol Radio, 2015).

Se podría pensar que, al contar el país con una estructura estatal renovada y asentada en las bases del capitalismo y el neoliberalismo, la situación de los conflictos sociales iba a mejorar, pero la realidad dista ampliamente de esas expectativas. En ese sentido, para tener una dimensión de la exigua contribución social que corrió por cuenta de las políticas de modernización, Sandoval (2005) registra durante el auge neoliberal (1980-1993) cerca de 1228 masacres en Colombia; acciones que son definidas como actos de liquidación física. Lo anterior explica cómo, aunque la modernización del Estado colombiano supuso concretar grandes cambios políticos y económicos, este proceso no logró impactar de la misma forma los problemas sociales.

Diversas movilizaciones sociales en Colombia han rechazado el lugar privilegiado que recibieron en su momento los asuntos económicos, una vez instalada la óptica capitalista y neoliberal. En el caso de la movilización estudiantil y profesional de la Contaduría Pública, se observa un panorama de insatisfacción por el rezago social que padece el país, el cual contrasta con el modo como los temas económicos y políticos se gestionan de manera efectiva.

Por su parte, el movimiento estudiantil contable que se encuentra reunido en la Fenecop revela un conjunto de problemas que se ciernen sobre la educación contable; inconvenientes que se relacionan principalmente con el contexto de modernización abordado, pues, según sostienen los estudiantes, cabe problematizar que el saber contable se enseñe teniendo como base lo funcional e instrumental. Lo anterior 
incide sobre la contabilidad entendida como rama de estudio, pues el orden social y económico condiciona su direccionamiento.

\section{La Contabilidad: condicionamiento y nemotecnia pedagógica}

Para Carlos Mario Ospina (2006), la Contabilidad es una disciplina que representa "la circulación de los elementos que reunidos indican el flujo de la riqueza de una determinada forma organizativa y social” (p. 162). Esta representación de la riqueza se comunica mediante sistemas de información, los cuales buscan satisfacer las necesidades informativas de usuarios internos y externos (Gómez, 2010).

En consecuencia, la representación contable de la realidad es susceptible a los cambios sociales, culturales y económicos del entorno, lo cual quiere decir que está vinculada con un contexto socioinstitucional (Gómez, 2010). De hecho, los diversos contextos socioinstitucionales de la historia han permitido el surgimiento y la evolución de múltiples sistemas de información contable — desde costes y gestión en el siglo XIX, hasta divulgación de información financiera en la actualidad-(Gómez, 2010; Gutiérrez, 2005). En tal escenario, la relación permanente que se teje entre la Contabilidad y el contexto socioinstitucional obedece a que el conocimiento contable interviene en la Economía, entendida como disciplina, y en el mismo grado en el derecho.

Por una parte, la contabilidad presenta relación con la economía cuando, por medio de la representación contable, orienta a los agentes en lo que respecta a la naturaleza económica del entorno, permitiendo además a los usuarios de la información contable analizar, interpretar y diseñar escenarios futuros. Para el profesor Gil (2010), "Economía y Contabilidad avanzan juntas acompañando las bases sustantivas de los inicios del desarrollo capitalista [...] como una racionalidad optimizadora de las decisiones” (p. 114).

Por otro lado, la contabilidad dice tener relación con el derecho cuando, a partir del derecho contable, ostenta la facultad de mediar y permitir el cumplimiento de los vínculos contractuales que celebran los diferentes agentes con las organizaciones (Gil, 2010; Sunder, 2005). En consonancia, el derecho contable está conformado de "una serie de reglas tecnológicas de contenido normativo que suelen aceptarse como un campo epistémico regional” (Gil, 2010, p. 107).

En un sentido cognoscitivo, la contabilidad ha presentado una relación constante con la economía y con el derecho. El motivo de esta cercanía disciplinal corresponde al carácter epistémico de la contabilidad, que según dichos parámetros es entendida como una tecnociencia social (Gil, 2010). De acuerdo también con Gil (2010), según el encuadre epistemológico bungeano de la tecnología, existe un "condicionamiento social por la política y la economía” (p. 122). Lo anterior significa que la economía y el derecho son disciplinas significativas para la contabilidad en tanto que esta las necesita "para formular su método propio, a fin de lograr una mejor descripción y comprensión de su objeto” (Gil, 2010, p. 117).

Según lo anterior, como tecnociencia social, la contabilidad tendrá en cuenta el condicionamiento político cuando el "desarrollo de las NIC [Normas Internacionales de Contabilidad sean] consecuencia de la inexorabilidad [de la globalización del derecho contable]" (Gil, 2010, p. 110), y tendrá en cuenta el condicionamiento económico, una vez la representación de las organizaciones se incline hacia el contenido financiero de estas. Tal es el caso actual de las circunstancias en las que la información contable responde al interés público, el cual es entendido según la óptica estandarizada de los mercados financieros como aquel conjunto de intereses de los inversores y acreedores (Gómez, 2010; Rueda, 2010; Zeff, 2003).

En suma, según el enfoque de la tecnociencia social, es posible entender la contabilidad como un saber científico condicionado que opera holísticamente con el Estado y el capital (Catchpowle, Cooper y Wright, 2004). Con base en esta perspectiva, se observa que el devenir de la profesión y de la disciplina contable ha estado condicionado a la evolución que refiere el contexto socioinstitucional del país (Gómez, 2010). 
De acuerdo con lo descrito, la concepción de contabilidad otorgada por el criterio tecnológico influye también en la educación contable, pues permite develar su estado de condicionamiento en términos del saber. En ese escenario, con el fin de respaldar las políticas de modernización, la educación contable centra su tarea pedagógica en la reproducción instrumental y funcional de las operaciones financieras necesarias para el funcionamiento empresarial; una postura surgida de una lógica capitalista y neoliberal (Bento, Mertins y White, 2017). En línea con lo anterior, se evidencia que no es prioridad de los organismos nacionales ni de los organismos que regulan la profesión contable propender en las aulas de clase por un cambio cultural y mental (Cruz, 2016) de los estudiantes, pues este cometido podría desviar los consabidos intereses económicos, políticos, científicos y técnicos que han sido defendidos en el país desde comienzos del siglo XX.

En ese sentido, la educación contable se ha visto en la difícil tarea de estudiar y enseñar universalmente ${ }^{5}$ un saber que ha estado condicionado socialmente por la política y la economía. Tal condicionamiento social, al que - valga la reiteración - se ha visto expuesta la contabilidad como tecnociencia, traza el proceso educativo que le corresponde como un camino predeterminado, delineado por la evolución económica del país y los avances institucionales del ejercicio contable. En suma, un desarrollo contable condicionado - es decir, puesto al servicio de los grupos económicos dominantes y del poder - orienta el propósito educativo contable hacia una labor nemotécnica que se concentra en capturar y difundir el "componente instrumental de la contabilidad, es decir [su] ejercicio práctico" (Grajales y Cuevas, 2010, p. 87) de la contabilidad.

\section{Análisis de las ponencias estudiantiles}

En los tres acápites previos se revelaron algunos argumentos que dan soporte al reconocimiento de una crisis social y educativa en el área. Esta crisis repercute en la enseñanza de la contabilidad, debido al singular estado de condicionamiento político y económico en el que esta se sitúa, por el contexto de modernización que se presenta en Colombia. En consecuencia, las ponencias estudiantiles sobre educación contable sustentadas en la Fenecop han buscado describir dicho estado de crisis social y educativa. Por esa razón, después de analizar las temáticas y los problemas desde donde los estudiantes han pensado la educación contable, se regresará a los argumentos esbozados en los acápites anteriores, para develar el sentido de las ponencias.

De acuerdo con lo anterior, resulta pertinente estudiar las ponencias estudiantiles de acuerdo con la óptica que suscitan las referencias tratadas hasta ahora. Lo anterior obedece a las sugerencias metodológicas del profesor Alexander Ruíz Silva (2006) en su trabajo “Texto, testimonio y metatexto: el análisis de contenido en la investigación en educación”, según lo cual el análisis de contenido hasta tanto trazado tiene el ánimo de "comprender la complejidad de la realidad social que se [estudió], en lugar de simplificarla y reducirla a mínimos esquemas de representación” (Ruíz, 2006, p. 45).

A lo largo del análisis de contenido, se realizaron dos revisiones bibliográficas: una para definir los referentes conceptuales y teóricos que guiaron la búsqueda de sentido en las ponencias, y otra para el análisis del corpus, que estaba compuesto de veintitrés ponencias. Dichos documentos corresponden a la comisión educativa, y han sido publicados en los libros de ponencias de los últimos catorce congresos nacionales de estudiantes de Contaduría Pública; eventos organizados por la Fenecop. ${ }^{6}$

Durante la revisión bibliográfica del corpus, se tuvieron en cuenta seis elementos de las ponencias para la identificación de sus temas: objetivos, marco de referencia, metodología, tesis central, conclusiones y mecanismos de acción. Vale la pena añadir que por cada elemento documentado se identificaron palabras claves que luego fueron confrontadas con los objetivos y el título del trabajo; tal fue el proceso que permitió definir cuáles serían los temas abordados. Una vez se fijó el listado de temas que correspondía a cada ponencia, se procedió a agruparlos según sus rasgos comunes. De esa clasificación se derivan las perspectivas temáticas del estudio, las cuales reflejan el enfoque del análisis adoptado por los estudiantes para aproximarse a la 
educación contable. Finalmente, con el fin de caracterizar las perspectivas temáticas del trabajo, le fueron asignados conceptos que cumplieron con la función de articularlo.

Por otro lado, durante la revisión bibliográfica del corpus que iba orientada hacia la identificación de los problemas de estudio, se realizó una segunda lectura completa de las ponencias; una revisión que tuvo en cuenta los hallazgos de las perspectivas temáticas. Cabe explicar que primero se realizó un análisis temático y posteriormente se procedió con el problémico, pues, una vez conocidas las perspectivas temáticas, era posible captar con mayor claridad los problemas educativos, en contrapartida con las áreas consultadas. De la segunda lectura fue posible extraer ochenta y cinco citas textuales en las que los estudiantes revelan cuáles son los problemas concretos de la educación contable. Con base en los elementos comunes de los problemas identificados, se agruparon las citas de tal modo que era posible distribuirlas en categorías analíticas. Dado que tales categorías también recogían elementos comunes, estas fueron sintetizadas en grupos analíticos.

\section{Temáticas para el abordaje de la educación contable}

A lo largo del presente estudio, las perspectivas temáticas se abordan en el orden que se presenta la tabla 1. En tanto, la descripción de las perspectivas temáticas incluye citas textuales de algunos trabajos del corpus que trasmiten el mensaje central de cada perspectiva. Asimismo, al final de la descripción se incluye el comentario del autor de este artículo, con el objetivo de condensar los aspectos críticos de cada perspectiva temática.

TABLA 1

Perspectivas temáticas para el abordaje de la educación contable

\begin{tabular}{clcc}
\hline $\mathbf{N .}^{\circ}$ & \multicolumn{1}{c}{ Perspectivas temáticas } & Temas & Ponencias \\
\hline \hline $\mathbf{1}$ & $\begin{array}{l}\text { La educación contable y su relación con aspectos políticos, } \\
\text { económicos, ambientales y culturales }\end{array}$ & 11 & 10 \\
\hline $\mathbf{2}$ & La formación en el saber contable: una apuesta por el sujeto & 7 & 7 \\
\hline $\mathbf{3}$ & Enseñanza de la contabilidad desde su dimensión conceptual & 6 & 5 \\
\hline $\mathbf{4}$ & Necesidad de integrar el currículo por medio de la praxis contable & 5 & 4 \\
\hline $\mathbf{5}$ & La mirada internacional en el saber contable: principales desafios & 2 & 2 \\
\hline $\mathbf{6}$ & El ejercicio ético en la Contaduría Pública & 2 & 2 \\
\hline
\end{tabular}


La educación contable y su relación con aspectos politicos, económicos, ambientales y culturales

TABLA 2

Perspectiva temática 1

\begin{tabular}{|c|c|c|c|}
\hline \begin{tabular}{c|} 
Año. \\
Congreso \\
\end{tabular} & Estudiantes & $\begin{array}{c}\text { Temas abordados en } \\
\text { las ponencias }\end{array}$ & Nombre de la ponencia \\
\hline $\begin{array}{l}2003 . \\
\text { XVII }\end{array}$ & $\begin{array}{l}\text { Danilo Rafael } \\
\text { Hernández }\end{array}$ & $\begin{array}{l}\text { Dimensión social de la } \\
\text { educación y la } \\
\text { universidad }\end{array}$ & $\begin{array}{l}\text { "Integración del conocimiento: observatorio de la } \\
\text { realidad posmoderna. Una mirada a la disciplina } \\
\text { contable" }\end{array}$ \\
\hline $\begin{array}{c}2008 . \\
\mathrm{XX}\end{array}$ & $\begin{array}{l}\text { John Jairo } \\
\text { Cuevas }\end{array}$ & $\begin{array}{l}\text { La empresa como un } \\
\text { todo que ordena en la } \\
\text { educación contable }\end{array}$ & $\begin{array}{l}\text { "La empresa como demiurgo de la educación del } \\
\text { profesional de la Contaduría Pública" }\end{array}$ \\
\hline $\begin{array}{l}2009 . \\
\text { XXI }\end{array}$ & \begin{tabular}{|l|} 
Francisco \\
Yesid \\
Asprilla \\
Torres \\
\end{tabular} & $\begin{array}{l}\text { Las dificultades que } \\
\text { enfrenta el pensamiento } \\
\text { contable }\end{array}$ & $\begin{array}{l}\text { "Administración y desarrollo del pensamiento } \\
\text { contable" }\end{array}$ \\
\hline $\begin{array}{l}2010 . \\
\text { XXII }\end{array}$ & $\begin{array}{l}\text { Johnny } \\
\text { Alexander } \\
\text { Acevedo } \\
\text { Alonso } \\
\end{array}$ & $\begin{array}{l}\text { Actualidad de la } \\
\text { educación en el } \\
\text { escenario de la } \\
\text { ideología dominante }\end{array}$ & $\begin{array}{l}\text { "Una aproximación a la actualidad de la } \\
\text { educación contable desde la óptica de la ideología } \\
\text { dominante" }\end{array}$ \\
\hline $\begin{array}{l}2012 . \\
\text { XXIII }\end{array}$ & \begin{tabular}{|l} 
Herman \\
Bernal \\
Artunduaga
\end{tabular} & $\begin{array}{l}\text { Proyección empresarial } \\
\text { en defensa de la } \\
\text { producción nacional }\end{array}$ & $\begin{array}{l}\text { "Cambio paradigmático en dos conceptos } \\
\text { globalizados del nuevo contador público" }\end{array}$ \\
\hline $\begin{array}{l}2014 . \\
\text { XXV }\end{array}$ & $\begin{array}{l}\text { Juan David } \\
\text { Franco }\end{array}$ & $\begin{array}{l}\text { Estudio al estado actual } \\
\text { de las competencias en } \\
\text { la educación superior }\end{array}$ & $\begin{array}{l}\text { "Educación y tensiones sociales en el siglo XXI: } \\
\text { una invitación a la reconstrucción moral del } \\
\text { espiritu cientifico" }\end{array}$ \\
\hline $\begin{array}{l}2014 . \\
X X V\end{array}$ & $\begin{array}{l}\text { Juan David } \\
\text { Franco }\end{array}$ & $\begin{array}{l}\text { Examen axiológico en } \\
\text { la pérdida de valores de } \\
\text { la educación }\end{array}$ & $\begin{array}{l}\text { "Educación y tensiones sociales en el siglo XXI: } \\
\text { una invitación a la reconstrucción moral del } \\
\text { espiritu cientifico" }\end{array}$ \\
\hline $\begin{array}{l}2015 . \\
\text { XXVI }\end{array}$ & $\begin{array}{l}\text { Sara Torres y } \\
\text { Jhojana } \\
\text { Usma }\end{array}$ & $\begin{array}{l}\text { Reconocimiento del } \\
\text { espacio socioambiental } \\
\text { y ecológico en la } \\
\text { educación y formación } \\
\text { contable }\end{array}$ & $\begin{array}{l}\text { "Perspectivas de la educación contable. Desafios } \\
\text { para el reconocimiento de los espacios } \\
\text { socioambientales en los programas de Contaduria } \\
\text { Pública en Colombia" }\end{array}$ \\
\hline $\begin{array}{l}2015 . \\
\text { XXVI }\end{array}$ & $\begin{array}{l}\text { Sandra } \\
\text { Milena } \\
\text { Acosta } \\
\text { Álvarez }\end{array}$ & $\begin{array}{l}\text { Contexto de emergencia } \\
\text { por lo público ante el } \\
\text { desplazamiento que } \\
\text { provoca el } \\
\text { neoliberalismo } \\
\end{array}$ & $\begin{array}{l}\text { "E1 componente público de la Contaduría Pública: } \\
\text { urgencia de la formación al respecto de un } \\
\text { elemento necesario para la transformación social" }\end{array}$ \\
\hline $\begin{array}{l}2016 . \\
\text { XXVII }\end{array}$ & $\begin{array}{l}\text { Mario Rodelo } \\
\text { y Candy } \\
\text { Chamorro }\end{array}$ & $\begin{array}{l}\text { Educación contable } \\
\text { instrumental, orientada } \\
\text { hacia la habilitación } \\
\text { técnica / laboral }\end{array}$ & $\begin{array}{l}\text { "Pensamiento crítico como elemento fundamental } \\
\text { en la formación contable y referente pedagógico } \\
\text { en el marco del Proceso de Paz" }\end{array}$ \\
\hline $\begin{array}{l}2016 . \\
\text { XXVII }\end{array}$ & $\begin{array}{l}\text { Leidy } \\
\text { Restrepo y } \\
\text { Margarita } \\
\text { Rodriguez }\end{array}$ & $\begin{array}{l}\text { E1 pensamiento } \\
\text { ambiental como opción } \\
\text { cultural ante el daño } \\
\text { natural, ambiental y } \\
\text { ecológico }\end{array}$ & $\begin{array}{l}\text { "Educación en contabilidad ambiental. Una } \\
\text { aproximación desde el pensamiento ambiental" }\end{array}$ \\
\hline
\end{tabular}

Fuente: elaboración propia

Según los estudiantes, la educación contable se encuentra "incubada en un nuevo orden que lo vincula todo a lo económico, pende del contexto" (Cuevas, 2008, p. 40) social del país, lo cual ocasiona que extravíe "su propósito esencial en términos de la inserción del hombre en la cultura, para venir a situarse en el 
propósito de la preparación de la mano de obra” (Cuevas, 2008, p. 44). En este sentido, se sostiene la necesidad de comprender "la realidad de una manera integral, sistémica, compleja, multidimensional [e] interdisciplinaria" (Hernández, 2003, p. 140) con el fin de enfrentar mediante la educación contable "los problemas del País" (Hernández, 2003, p. 140).

De acuerdo con lo anterior, según los estudiantes, al enseñar la contabilidad de acuerdo con un panorama más cercano a las variables sociales, se podrá trasmitir un "saber que coadyuve al desarrollo y el aumento en la calidad de vida del ser humano, sin dañar el ambiente" (Hernández, 2003, p. 140). Se debe entonces aunar esfuerzos para consolidar "un plan de estudios identificado por los diversos procesos económicos, sociales, políticos, culturales e investigativos" (Rodelo y Chamorro, 2016, p. 104).

Comentario: Según esta perspectiva, los estudiantes conciben el estado de la sociedad principalmente de acuerdo con cuatro aspectos: el político, el económico, el ambiental y el cultural. En ese sentido, los autores de las ponencias aquí clasificadas abordan el lugar que ocupa el contexto social en la educación contable.

En tanto, la relación planteada entre sociedad y educación contable esboza un escenario con dos orientaciones: lo anhelado y lo impuesto. Según ese esquema, los estudiantes anhelan una educación contable que capte las necesidades del país y sus problemáticas, para avanzar con una mirada integral de las organizaciones y del saber contable. Sin embargo, cuando observan la realidad, se encuentran con una educación contable centrada en la instrucción funcional que ha impuesto el contexto colombiano. 


\section{La formación en el saber contable: una apuesta por el sujeto}

TABLA 3

Perspectiva temática 2

\begin{tabular}{|c|c|c|c|}
\hline $\begin{array}{c}\text { Año. } \\
\text { Congreso }\end{array}$ & Estudiantes & $\begin{array}{c}\text { Temas abordados en } \\
\text { las ponencias }\end{array}$ & Nombre de la ponencia \\
\hline $\begin{array}{l}2001 \\
\text { XV }\end{array}$ & $\begin{array}{l}\text { Constanza } \\
\text { Gómez y } \\
\text { Carlos } \\
\text { Muñoz }\end{array}$ & $\begin{array}{l}\text { Alcance e importancia } \\
\text { de la formación } \\
\text { integral }\end{array}$ & $\begin{array}{l}\text { "La formación integral en Contaduría Pública: } \\
\text { elemento fundamental para la construcción de un } \\
\text { nuevo pais" }\end{array}$ \\
\hline $\begin{array}{l}2004 . \\
\text { XVIII }\end{array}$ & $\begin{array}{l}\text { Juan } \\
\text { Manuel } \\
\text { Pineda } \\
\text { López }\end{array}$ & $\begin{array}{l}\text { Sentido de la } \\
\text { formación integral y } \\
\text { de la formación } \\
\text { investigativa }\end{array}$ & $\begin{array}{l}\text { "Intereses subyacentes de la propuesta de } \\
\text { estandarización de la educación contable" }\end{array}$ \\
\hline $\begin{array}{l}2010 \\
\text { XXII }\end{array}$ & $\begin{array}{l}\text { Harrison } \\
\text { Daza } \\
\text { Londoño }\end{array}$ & $\begin{array}{l}\text { Las problemáticas } \\
\text { sociales que suscribe } \\
\text { la urgencia en } \\
\text { formación política }\end{array}$ & $\begin{array}{l}\text { "La educación contable alternativa: entre la urgencia } \\
\text { del adiestramiento instrumental y la emergencia de la } \\
\text { formación disciplinal" }\end{array}$ \\
\hline $\begin{array}{l}2013 . \\
\text { XXIV }\end{array}$ & $\begin{array}{l}\text { Natalia } \\
\text { Gallón } \\
\text { Vargas }\end{array}$ & $\begin{array}{l}\text { Desarrollo dela } \\
\text { educación contable } \\
\text { desde la formación } \\
\text { ciudadana }\end{array}$ & $\begin{array}{l}\text { "La formación ciudadana en el contador público: una } \\
\text { apuesta ineludible desdela educación filosófica y } \\
\text { democrática" }\end{array}$ \\
\hline $\begin{array}{l}2015 . \\
\text { XXVI }\end{array}$ & $\begin{array}{l}\text { Sara Torres } \\
\text { y Jhojana } \\
\text { Usma }\end{array}$ & $\begin{array}{l}\text { El sujeto contable en } \\
\text { el acto educación- } \\
\text { formación, con miras } \\
\text { al espacio } \\
\text { socioambiental }\end{array}$ & $\begin{array}{l}\text { "Perspectivas de la educación contable. Desafios para } \\
\text { el reconocimiento de los espacios socioambientales en } \\
\text { los programas de Contaduría Pública en Colombia" }\end{array}$ \\
\hline $\begin{array}{l}2016 . \\
\text { XXVII }\end{array}$ & $\begin{array}{l}\text { Mario } \\
\text { Rodelo y } \\
\text { Candy } \\
\text { Chamorro }\end{array}$ & $\begin{array}{l}\text { Necesidad de un } \\
\text { proceso educativo } \\
\text { contable basado en el } \\
\text { pensamiento crítico }\end{array}$ & $\begin{array}{l}\text { "Pensamiento crítico como elemento fundamental en } \\
\text { la formación contable y referente pedagógico en el } \\
\text { marco del Proceso de Paz" }\end{array}$ \\
\hline $\begin{array}{l}2016 . \\
\text { XXVII }\end{array}$ & $\begin{array}{l}\text { María } \\
\text { Victoria } \\
\text { Rodríguez } \\
\text { Chacón }\end{array}$ & $\begin{array}{l}\text { La educación y la } \\
\text { formación en } \\
\text { Contaduría Pública } \\
\text { desde el cultivo de } \\
\text { emociones y el } \\
\text { pensamiento crítico }\end{array}$ & $\begin{array}{l}\text { "El sentipensar latinoamericano, una apuesta por el } \\
\text { pensamiento crítico de la formación-educación en } \\
\text { contabilidad" }\end{array}$ \\
\hline
\end{tabular}

Fuente: elaboración propia

De acuerdo con lo expuesto, los estudiantes organizan una serie de referencias en torno a la búsqueda de una formación que posibilite "un individuo mejor capacitado, más competitivo en su área de trabajo, consciente de su responsabilidad social, poseedor de un pensamiento crítico y analítico acerca de la realidad humana, social y empresarial" (Gómez y Muñoz, 2001, p. 165). En consecuencia, esta formación surge porque los estudiantes ponen en evidencia una educación contable que promueve la "lógica de la racionalidad productivo-instrumental y la lógica del mercado” (Gómez y Muñoz, 2001, p. 165).

En palabras de los estudiantes, la formación del sujeto en el saber contable supone contemplar "las tensiones y dramas que subyacen en el ir y venir del mundo actual [...] y compartir un mundo en común [para] aportar, desde su saber y profesión, a la realización de una sociedad mejor" (Gallón, 2013, p. 117). De acuerdo con lo anterior, los estudiantes consideran que el rol de las instituciones es velar por la formación de "un sujeto responsable y sensible, pero sobre todo un ciudadano íntegro y consciente del espacio en el que se desarrolla" (Torres y Usma, 2015, p. 95); con ello se fomentaría "la comprensión humana de los virajes y 
orientaciones que se le pueda dar a las emociones, que influyen positiva o negativamente el accionar del ser humano contable" (Rodríguez, 2016, p. 141).

Comentario: De acuerdo con una imposición, según la cual el contexto social ha condicionado la educación contable - lo cual funda una perspectiva temática-, los estudiantes observan las dificultades que se le presentan a la tarea educativa para llevar a cabo un proceso formativo verdaderamente integrador. Dicho proceso supondría la compaginación de los aspectos tecnológicos, disciplinares, contextuales y éticos que están inmersos en el ejercicio de la contabilidad.

En consonancia, en el estudiante de Contaduría Pública se evidencia un bajo nivel de reflexión crítica en cuanto a su entorno se refiere, pues la educación que recibe lo ubica en una racionalidad formulada con arreglo a determinados fines; una racionalidad que se caracteriza por su neutralidad ante los conflictos humanos y éticos de la sociedad. Cabe añadir que dicha lógica no promueve la elaboración estética del "yo" como un acto de formación.

\section{La enseñanza de la contabilidad desde su dimensión conceptual}

TABLA 4

Perspectiva temática 3

\begin{tabular}{|c|c|c|c|}
\hline \begin{tabular}{c|} 
Año. \\
Congreso
\end{tabular} & Estudiantes & Temas abordados en las ponencias & Nombre de la ponencia \\
\hline 2003. XVII & $\begin{array}{l}\text { Danilo } \\
\text { Rafael } \\
\text { Hernández }\end{array}$ & $\begin{array}{l}\text { Estudio de la interdisciplinariedad y la } \\
\text { transdisciplinariedad }\end{array}$ & $\begin{array}{l}\text { "Integración del conocimiento: } \\
\text { Observatorio de la Realidad } \\
\text { Posmodema. Una mirada a la } \\
\text { disciplina contable" }\end{array}$ \\
\hline 2007. XIX & $\begin{array}{l}\text { Sergio Luis } \\
\text { Ordoñez } \\
\text { Noreña }\end{array}$ & $\begin{array}{l}\text { Importancia del estudio disciplinal } \\
\text { para la educación contable }\end{array}$ & $\begin{array}{l}\text { "El énfasis de lo disciplinar sobre lo } \\
\text { profesional para la formación del } \\
\text { contador público: una experiencia en } \\
\text { formación contable" }\end{array}$ \\
\hline 2007. XIX & $\begin{array}{l}\text { Sergio Luis } \\
\text { Ordoñez } \\
\text { Noreña }\end{array}$ & $\begin{array}{l}\text { La enseñanza y la pedagogía vistas } \\
\text { desde la disciplina contable }\end{array}$ & $\begin{array}{l}\text { "El énfasis de lo disciplinar sobre lo } \\
\text { profesional para la formación del } \\
\text { contador público: una experiencia en } \\
\text { formación contable" }\end{array}$ \\
\hline 2014. XXV & \begin{tabular}{|l} 
Daniela \\
Londoño, \\
Deicy Lopez \\
y Catalina \\
Moreno \\
\end{tabular} & $\begin{array}{l}\text { Vínculo entre contabilidad y } \\
\text { argumentación: compresión } \\
\text { disciplinal }\end{array}$ & $\begin{array}{l}\text { "La contabilidad y las teorías de la } \\
\text { argumentación: una taxonomía para } \\
\text { el devenir formativo" }\end{array}$ \\
\hline $\begin{array}{l}2015 . \\
\text { XXVI }\end{array}$ & $\begin{array}{l}\text { Sandra } \\
\text { Milena } \\
\text { Acosta } \\
\text { Álvarez }\end{array}$ & $\begin{array}{l}\text { Problemáticas de la contaduría } \\
\text { pública ante el deber de representar } \\
\text { información pública }\end{array}$ & $\begin{array}{l}\text { "El componente público de la } \\
\text { Contaduría Pública: urgencia de la } \\
\text { formación al respecto de un elemento } \\
\text { necesario para la transformación } \\
\text { social" }\end{array}$ \\
\hline $\begin{array}{l}2016 . \\
\text { XXVII }\end{array}$ & $\begin{array}{l}\text { María } \\
\text { Victoria } \\
\text { Rodríguez } \\
\text { Chacón } \\
\end{array}$ & $\begin{array}{l}\text { El saber pensar en contabilidad como } \\
\text { promotor dela comprensión humana }\end{array}$ & $\begin{array}{l}\text { "El sentipensar latinoamericano, una } \\
\text { apuesta por el pensamiento crítico de } \\
\text { la formación-educación en } \\
\text { contabilidad" }\end{array}$ \\
\hline
\end{tabular}

Fuente: elaboración propia

Las ponencias aquí clasificadas reconocen la urgencia de una enseñanza conceptual de la contabilidad, pues los estudiantes han sido partícipes de un aprendizaje reducido "exclusivamente al ámbito de los códigos y las cifras monetarias” (Londoño, López y Moreno, 2014, p. 147); un accionar en el que el ejercicio pedagógico 
se recrea con el único propósito de que el estudiante llegue a ganar habilidades como "tenedor de libros, [para] memorizar cuentas y realizar balances", de modo que se "desconocen aspectos consustanciales a la disciplina, como es el caso de la partida doble y la cuenta” (Ordoñez, 2007, p. 47). Conceptualmente, para enseñar contabilidad se requiere "conocer, o al menos entender, el contexto histórico, social y político de la contabilidad" (Londoño et al., 2014). En ese sentido, bajo un enfoque conceptual se concibe a la contabilidad de acuerdo con "otras posibilidades argumentativas, otros discursos, otros códigos y símbolos, con los cuales el sujeto contable podría construir otro tipo de realidad social” (Londoño et al., 2014).

Comentario: Para los estudiantes, la enseñanza universitaria de la contabilidad debe cimentarse en la trasmisión de un saber conceptual que fomente su construcción como disciplina del conocimiento. Asimismo, los ponentes consideran que la contabilidad ha sido entendida tradicionalmente como una herramienta indispensable en el desarrollo económico, hasta el punto de perfilarse como el lenguaje de los negocios. En tal escenario, con el fin de enseñar la contabilidad según el propósito antes descrito, no hace falta desplegar un análisis pedagógico en el aula; basta con replicar la aritmética de la ecuación contable. En ese plano, los estudiantes advierten que la educación contable no puede desentenderse de la ecuación contable, pues los aspectos tecnológicos y técnicos son vitales para la disciplina; sin embargo, sostienen además que los esfuerzos pedagógicos exigen otras miradas que pueden indicar los peligros y las tensiones del propio equilibrio aritmético de la contabilidad.

\section{Necesidad de integrar el curriculo por medio de la praxis contable}

TABLA 5

Perspectiva temática 4

\begin{tabular}{|c|c|c|c|}
\hline \begin{tabular}{c|} 
Año. \\
Congreso
\end{tabular} & Estudiantes & \begin{tabular}{|c|} 
Temas abordados en las \\
ponencias
\end{tabular} & Nombre de la ponencia \\
\hline \begin{tabular}{l|}
2007. \\
XIX
\end{tabular} & $\begin{array}{l}\text { Jhon Cuevas y } \\
\text { Jhonny Grajales }\end{array}$ & $\begin{array}{l}\text { Contexto en el que está } \\
\text { inmersa la enseñanza de la } \\
\text { teoría contable }\end{array}$ & $\begin{array}{l}\text { "El pensamiento único y su relación con } \\
\text { la formación del estudiante de Contaduría } \\
\text { Pública en el área de teoría contable" }\end{array}$ \\
\hline $\begin{array}{l}2007 . \\
\text { XIX }\end{array}$ & $\begin{array}{l}\text { Jhon Cuevas y } \\
\text { Jhonny Grajales }\end{array}$ & $\begin{array}{l}\text { Elementos que ocasionan } \\
\text { el rechazo de la teoría } \\
\text { contable }\end{array}$ & $\begin{array}{l}\text { "El pensamiento único y su relación con } \\
\text { la formación del estudiante de Contaduría } \\
\text { Pública en el área de teoría contable" }\end{array}$ \\
\hline $\begin{array}{l}2009 \\
\text { XXI }\end{array}$ & $\begin{array}{l}\text { William Andrés } \\
\text { Polo Díaz }\end{array}$ & \begin{tabular}{|l|} 
El currículo como \\
elemento primordial en las \\
prácticas de la enseñanza
\end{tabular} & $\begin{array}{l}\text { "Características del curriculum en la } \\
\text { educación del profesional de la } \\
\text { Contaduría Pública" }\end{array}$ \\
\hline $\begin{array}{l}2012 . \\
\text { XXIII }\end{array}$ & $\begin{array}{l}\text { Johnny Alexander } \\
\text { Acevedo Alonso }\end{array}$ & \begin{tabular}{|l|} 
Importancia delas \\
Ciencias Sociales y la \\
Literatura en la educación \\
contable
\end{tabular} & $\begin{array}{l}\text { "La necesidad de la Literatura y las } \\
\text { Ciencias Sociales en la formación del } \\
\text { estudiante de Contaduría Pública" }\end{array}$ \\
\hline $\begin{array}{l}2016 . \\
\text { XXVII }\end{array}$ & \begin{tabular}{|l|} 
Leidy Restrepoy \\
Margarita \\
Rodríguez \\
\end{tabular} & $\begin{array}{l}\text { Necesidad de incluir en la } \\
\text { educación contable el } \\
\text { pensamiento ambiental }\end{array}$ & $\begin{array}{l}\text { "Educación en contabilidad ambiental. } \\
\text { Una aproximación desde el pensamiento } \\
\text { ambiental" }\end{array}$ \\
\hline
\end{tabular}

Fuente: elaboración propia

Para los ponentes, por medio de los planes de estudio, los programas académicos de Contaduría Pública han buscado "adiestrar a los estudiantes para que puedan insertarse con facilidad en el mundo organizativo [y de ese modo] satisfacer sus necesidades de información financiera” (Polo, 2007, p. 208). Es así como las instituciones, por medio de estos diseños curriculares de tipo "técnico instrumental [,] reproducen una enseñanza para el sistema, es decir, para formar mano de obra irreflexiva que solo siga instrucciones" (Acevedo, 2012, p. 139). En consecuencia, los currículos en educación contable son "tecnocráticos, por lo que su enfoque 
debe cambiar hacia prácticas pedagógicas que establezcan diálogos con los diferentes saberes y así contribuir al mejoramiento de la sociedad" (Polo, 2007, p. 210).

De acuerdo con lo expuesto, aspectos como la teoría contable (Cuevas y Grajales, 2007), las ciencias humanas y la literatura (Acevedo, 2012), servirían de elementos pluridimensionales que podrían ampliar el horizonte relegado por el pensamiento único, que se ha instalado en la mentalidad de los estudiantes (Cuevas y Grajales, 2007). Este panorama ha fundado relaciones dicotómicas entre el ejercicio de la Contaduría Pública (prácticas) y el conocimiento contable (teorias) (Cuevas y Grajales, 2007).

Comentario: En el sentido descrito, los planteamientos sustentados buscan advertir a la comunidad universitaria sobre un proyecto educativo contable cuya única intención es preparar mano de obra irreflexiva para el mantenimiento y la reproducción del capital. Según esa perspectiva, los estudiantes han pensado en la necesidad de integrar el currículo del saber contable, mediante el desarrollo sinérgico del conocimiento práctico contable con el conocimiento social, político, cultural y humanístico propio de la esfera universitaria en la cual la profesión es enseñada.

\section{La mirada internacional en el saber contable: principales desafios}

TABLA 6

Perspectiva temática 5

\begin{tabular}{|c|c|c|c|}
\hline \begin{tabular}{c|} 
Año. \\
Congreso
\end{tabular} & Estudiantes & $\begin{array}{c}\text { Temas abordados en las } \\
\text { ponencias }\end{array}$ & Nombre de la ponencia \\
\hline $\begin{array}{l}2002 . \\
\text { XVI }\end{array}$ & $\begin{array}{l}\text { Diego Fernando } \\
\text { Duque Ramírez }\end{array}$ & $\begin{array}{l}\text { Perspectivas generales de la } \\
\text { educación contable }\end{array}$ & $\begin{array}{l}\text { "Medios y fines de la educación } \\
\text { contable: una mirada culturalista" }\end{array}$ \\
\hline $\begin{array}{l}2004 . \\
\text { XVIII }\end{array}$ & $\begin{array}{l}\text { Juan Pineda y } \\
\text { Claudia Calderón }\end{array}$ & $\begin{array}{l}\text { Estandarización en educación } \\
\text { contable }\end{array}$ & $\begin{array}{l}\text { "Intereses subyacentes de la Propuesta de } \\
\text { Estandarización de la Educación } \\
\text { Contable" }\end{array}$ \\
\hline
\end{tabular}

Fuente: elaboración propia

$\mathrm{Al}$ respecto, los estudiantes consideran que "las propuestas de estandarización de la educación contable conllevan a la estandarización de la mano de obra; impiden que los individuos cuestionen el sistema establecido, lo que no permite el desarrollo de un ser autónomo, propositivo y con criterio" (Pineda y Calderón, 2004, p. 142). Según esta perspectiva, es difícil que el saber contable logre "encarnar el sentido de los bienes culturales de su comunidad" (Duque, 2002, p. 68), porque se pierde el interés de generar información que beneficie el bienestar social, ya que, de acuerdo con la perspectiva internacional, lo más importante es crear valor financiero.

Comentario: Los organismos de regulación contable y de aseguramiento han globalizado sus prácticas, lo que les permite diseminar sus principios de buen gobierno al mundo financiero y económico. En ese plano, los estudiantes consideran que tal proceso es un aspecto inherente al sistema capitalista; por ende, la expansión de dicha lógica está asociada con el poder político de estos organismos. Es así como la mirada internacional trae consigo un enfoque que privilegia el utilitarismo de la información y del pensamiento. La improcedencia de esta mirada consiste en que habilita al estudiante para adentrarse en el dominio útil de los instrumentos organizacionales, sin explicarles el sentido de tales instrumentos. 


\section{El ejercicio ético en la Contaduría Pública}

TABLA 7

Perspectiva temática 6

\begin{tabular}{l|l|l|l}
\hline $\begin{array}{c}\text { Año. } \\
\text { Congreso }\end{array}$ & \multicolumn{1}{|c|}{ Estudiantes } & $\begin{array}{c}\text { Temas abordados en las } \\
\text { ponencias }\end{array}$ & \multicolumn{1}{c}{ Nombre de la ponencia } \\
\hline \hline 2003. & Julian Andrés & $\begin{array}{l}\text { Educación ética en la } \\
\text { Contaduría Pública }\end{array}$ & $\begin{array}{l}\text { "Elementos conceptuales para una } \\
\text { propuesta pedagógica en la formación } \\
\text { ética del estudiante de Contaduría } \\
\text { Pública" }\end{array}$ \\
\hline $\begin{array}{l}\text { Gómez } \\
\text { XXI }\end{array}$ & $\begin{array}{l}\text { Marlon David } \\
\text { García Jiménez }\end{array}$ & $\begin{array}{l}\text { Influencia de la ética en el } \\
\text { ejercicio contable }\end{array}$ & $\begin{array}{l}\text { "Problemas éticos del contador público y } \\
\text { su relevancia social" }\end{array}$ \\
\hline
\end{tabular}

Fuente: elaboración propia

Como lo evidencia el acervo conceptual explorado, los autores de las ponencias expresan una preocupación latente por el actuar del contador público, lo cual es reflejo de los altos índices de corrupción y de manipulación de la información contable. En ese sentido, los autores postulan la importancia de "definir los aspectos para la actuación correcta sin el peso jurídico que siempre ha primado en la definición moral y ética en el ejercicio contable" (García, 2009, p. 219). Con base en la prudencia y la transparencia, el profesional de Contaduría Pública obtendría grandes "logros en cuanto al manejo racional y adecuado de la información y el control, así, una firme formación ética le permitiría alejar a la profesión del empirismo y acercarla a su deber ser disciplinal" (Gómez, 2003, p. 164).

Comentario: En esta selección de ponencias, los estudiantes se acercan al tema educativo de la ética. De acuerdo con esa aproximación, rechazan que esta sea impartida en las aulas mediante la exposición de las consecuencias jurídicas que acarrea cometer un error en el ejercicio contable. Por tanto, insisten en la necesidad de cambiar esa manera de concebir la ética; sugieren comprenderla como un acto humano (subjetivo) con repercusiones sociales (objetivo), pues solamente de ese modo se le enseña al estudiante de Contaduría Pública a pensar en los riesgos subyacentes a la objetividad e independencia vinculados con su quehacer.

\section{Síntesis temática}

Las perspectivas temáticas fueron recogidas de acuerdo con cuatro conceptos fundamentales:

1. Sociedad: noción según la cual los estudios de educación contable abarcan lo político, lo económico, lo ambiental y lo cultural de la sociedad.

2. Contabilidad: concepto de acuerdo con el cual los estudiantes consultan lo esencial de la contabilidad para entender su propósito disciplinal, y así buscar caminos para su enseñanza.

3. Sujeto: según esta noción, los trabajos hacen referencia al estudio del sujeto contemporáneo que se enfrenta a los horizontes educativos.

4. Contaduría Pública: concepto que cabe señalar separadamente, ante la necesidad de mirar de manera crítica el ejercicio profesional.

En ese escenario, la perspectiva 1, la cual refleja el vínculo existente entre la educación contable y la sociedad, y la perspectiva 5, que señala aspectos de regulación y del modelo económico, hacen referencia al concepto de la sociedad. Otro es el caso de la perspectiva 3, la cual aborda el tema de la enseñanza en la contabilidad, y la perspectiva 4, que concierne a la necesidad de integrar el saber contable; ambas perspectivas se relacionan 
con el concepto de la contabilidad. Por su parte, la perspectiva 2 estudia la formación del sujeto en el saber contable, por eso se puede sostener que está inmersa en el estudio del sujeto. Por último, la perspectiva 6 hace referencia a la contaduría pública porque enfatiza lo que es propio del ejercicio profesional. En ese sentido, la figura 1 expone una síntesis temática:

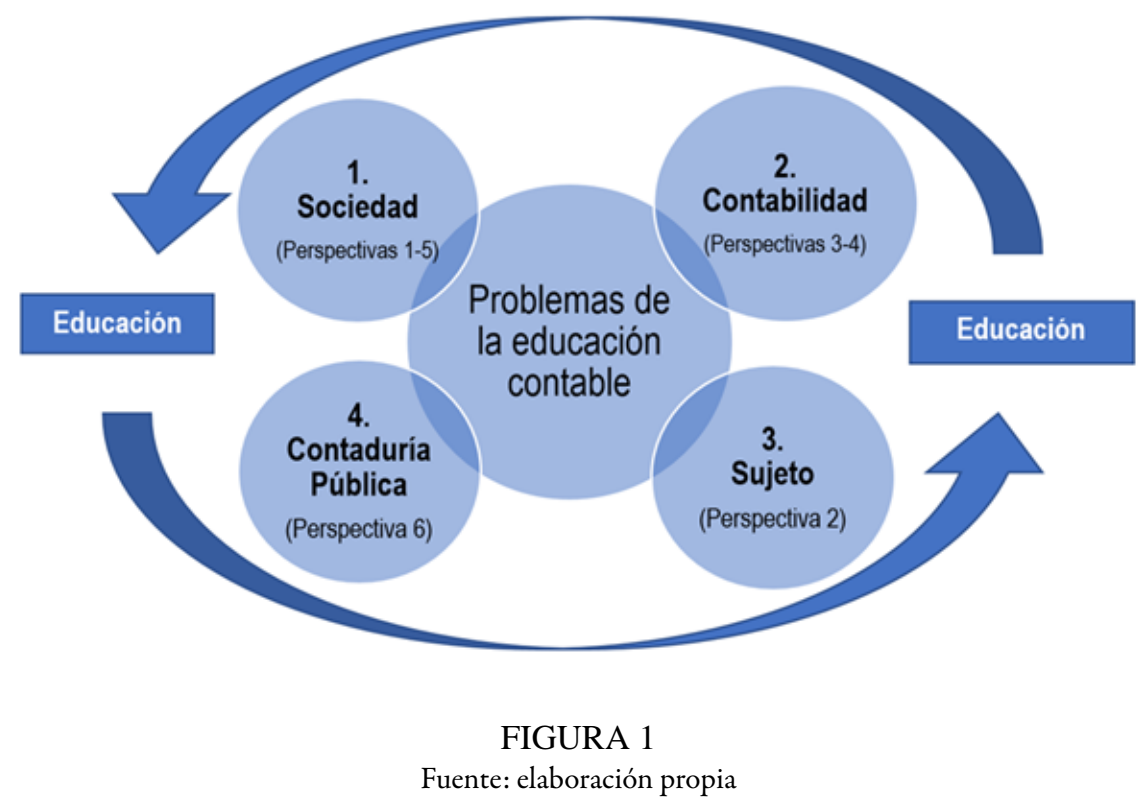

\section{Problemas de la educación contable}

A continuación, la tabla 8 presenta las categorías y los grupos analíticos acorde con los cuales los estudiantes exponen los problemas concretos de la educación contable. En tanto, la descripción de los grupos analíticos incluye citas textuales de algunos trabajos del corpus que transmiten los problemas centrales de cada grupo. Al final de cada descripción se encuentra un comentario del autor de este artículo; anotación con la cual se busca reunir los aspectos críticos de cada grupo analítico de problemas. 
TABLA 8

Grupo analítico y categorías: problemas de la educación contable

\begin{tabular}{|c|c|c|c|c|}
\hline N. ${ }^{\circ}$ & Grupo analítico & No. & Categorías analíticas & Citas \\
\hline \multirow{5}{*}{1} & \multirow{5}{*}{ Contexto y currículo } & 1.1 & $\begin{array}{l}\text { Grupos económicos como referente } \\
\text { educativo }\end{array}$ & 17 \\
\hline & & 1.2 & Ausencia de investigación contable & 10 \\
\hline & & 1.3 & Currículo asignaturista y no articulado & 8 \\
\hline & & 1.4 & Dicotomía entre teoría y práctica & 8 \\
\hline & & 1.5 & $\begin{array}{l}\text { Discurso educativo coyuntural y } \\
\text { limitado }\end{array}$ & 5 \\
\hline \multirow{4}{*}{2} & \multirow{4}{*}{ Pedagogía } & 2.1 & Carencia de concientización social & 12 \\
\hline & & 2.2 & Carencia de concientización crítica & 4 \\
\hline & & 2.3 & $\begin{array}{l}\text { Carencia de concientización } \\
\text { investigativa }\end{array}$ & 2 \\
\hline & & 2.4 & Carencia de concientización empresarial & 1 \\
\hline \multirow{3}{*}{3} & \multirow{3}{*}{ Enseñanza } & 3.1 & Enseñanza con énfasis instrumental & 12 \\
\hline & & 3.2 & Enseñanza con énfasis normativo & 4 \\
\hline & & 3.3 & Enseñanza con énfasis financiero & 2 \\
\hline
\end{tabular}

Fuente: elaboración propia

Contexto y curriculo

TABLA 9

Grupo analítico 1

\begin{tabular}{c|l|c|c}
\hline $\mathbf{N} .^{\circ}$ & \multicolumn{1}{|c|}{ Categoría analítica } & Citas & Ponencias \\
\hline \hline 1.1 & Grupos económicos como referente educativo & 17 & $4,5,6,8,9,12,13,16,17,21,22$ \\
\hline 1.2 & Ausencia de investigación contable & 10 & $1,3,5,7,14,16,20,22$ \\
\hline 1.3 & Currículo asignaturista y no articulado & 8 & $1,3,8,12,14,19,20,22$ \\
\hline 1.4 & Dicotomía entre teoría y práctica & 8 & $1,2,5,6,7,12$ \\
\hline 1.5 & Discurso educativo coyuntural y limitado & 5 & $2,10,19,23$ \\
\hline
\end{tabular}

Fuente: elaboración propia

El primer grupo consta de cinco categorías, la primera de las cuales problematiza el nivel de influencia que ejercen los grupos económicos en la concepción educativa de la Contaduría Pública. Particularmente, se sostiene en esta categoría que "quienes están fijando los estándares que determinan la calidad de [los] programas académicos, en el fondo son los gremios económicos" (Pineda y Calderón, 2004, p. 141). De ese modo, se hace mención de una educación contable que "parece imbricarse estrictamente en habilitar [al] estudiante [para] el uso de herramientas que le permitan satisfacer las necesidades de información financiera de las empresas" (Cuevas, 2008, p. 39); es así como "la educación contable sigue preocupada por entregarle al mercado profesionales muy excelentes en [el ejercicio] contable y en la empresa como el campo más predominante para dicha práctica" (Restrepo y Rodríguez, 2016, p. 127). En ese sentido, las ponencias que están agrupadas en esta categoría sostienen que los grupos económicos determinan la educación contable: "qué se enseña, cómo se enseña y para qué se enseña" (Daza, 2010, p. 44). 
En la segunda categoría, que se dedica a la ausencia de investigación contable, se observa el malestar que causa la insistencia docente e institucional en el dominio del "hacer [contable] y no [aquella misma disposición] para el pensar por qué se hace" (Acevedo, 2012, p. 145). En ese sentido, el panorama que le corresponde a la contabilidad en la actual educación contable responde a la imagen rezagada que tiene desde lo "normativo [y] monodisciplinario"; aspecto que imprime entonces "su incapacidad para develar la estrecha relación [que tiene] con la historia, la epistemología [y con] las ciencias sociales” (Gallón, 2013, p. 118). En suma, la ausencia de investigación contable da lugar a que "los estudiantes no [piensen] la contabilidad como una disciplina social que entra en diálogo con otras disciplinas" y la lleva a estar "aislada de las construcciones sociales" (Restrepo y Rodríguez, 2016, p. 128).

La tercera categoría corresponde a los problemas que se concentran en los curriculos asignaturistas y no articulados. Se enfatiza en tales ponencias la necesidad de problematizar los currículos en la Contaduría Pública, pues han creado "un reduccionismo en la comprensión del mundo y de la disciplina en el estudiante" (Acevedo, 2012, pp. 141-142). Además, cabe añadir que los currículos no han logrado "precisar los núcleos básicos en donde descansa la relación ontológica entre el ideal del Contador Público y las disciplinas o ciencias que en su articulación lo hacen posible" (Cuevas, 2008, p. 43). De acuerdo con lo anterior, en estas ponencias se observa cómo "los currículos de Contaduría Pública, [...] reducen la visión de la Contabilidad hacia un fin netamente financiero [y] dejan de lado la construcción de un pensamiento crítico" (Acevedo, 2012, p. 145). Incluso, sostienen los estudiantes que en el currículo "se evidencia una ausencia tácita [...] del componente público en todas las variables [de las cuales se ocupa]" (Acosta, 2015, p. 112).

La cuarta categoría, que versa sobre la dicotomía existente entre teoría y práctica, presenta la inconformidad ante la prioridad otorgada a "la profesionalización de la disciplina", mientras que el "desarrollo teórico de la contabilidad como disciplina” (Pineda y Calderón, 2004, p.137) queda relegado y subvalorado. En concordancia, las ponencias expresan que la balanza, que debe mostrar un equilibrio entre lo teórico y lo práctico del saber contable, se inclina más hacia lo práctico, debido a que los programas académicos no "fomentan a cabalidad un proceso de formación, más [bien] parecen orientados a 'entrenar' contadores” (Pineda y Calderón, 2004, p. 137).

En la última categoría, que se concentra en el discurso educativo coyuntural y limitado, se sostiene que "la debilidad principal del discurso educativo contable radica en su carácter marcadamente coyuntural y de visión limitada" (Duque, 2002, p. 63); dicha insuficiencia se debe a que en "el medio educativo contable existe una sumatoria de prejuicios que ahogan la facultad del sujeto para obtener una capacidad de valorar éticamente su entorno" (García, 2009, p. 220), lo cual lleva a que rutinariamente se conciba el saber contable según el discernimiento de "problemas legales [y la representación de la] conveniencia económica” (García, 2009, p. 221). Es así como "los programas de Contaduría Pública no tienen en cuenta el estatus sensible-emocional de los estudiantes" (Rodríguez, 2016, p. 129) y se enfocan en instruir a "seres inertes e inconscientes con respecto de su compromiso como sujetos contables para el mundo" (Torres y Usma, 2015, p. 94).

Comentario: Es posible observar en este grupo de categorías las problemáticas que se derivan del estudio contextual de la época y de su relación con la educación contable. De acuerdo con esa exposición de ideas, los grupos económicos resultan ser sumamente importantes, pues determinan el sentido y la orientación de los programas académicos de Contaduría Pública. Identificado lo anterior, es posible atisbar un estadio de interdependencia entre la educación contable y los grupos económicos. En consecuencia, el interés formativo que se condensa en el saber contable queda relegado, mientras que el interés del mercado y del sector productivo termina por ser privilegiado en las aulas.

Asimismo, los ponentes plantean que gran cantidad de estudiantes y docentes asumen la imposición antes descrita, y deciden autodenominarse 'profesionales prácticos'. Dado ese panorama, para la educación contable la investigación crítica y reflexiva adquiere un carácter de poco reconocimiento y valoración, porque 
el contexto no busca potenciarla. En suma, los ejercicios intelectuales resultan de poca utilidad para el sistema social y económico capitalista.

\section{Pedagogía}

TABLA 10

Grupo analítico 2

\begin{tabular}{c|l|c|c}
\hline $\mathbf{N .}{ }^{\circ}$ & \multicolumn{1}{|c|}{ Categoría analítica } & Citas & Ponencias \\
\hline \hline 2.1 & Carencia de concientización social & 12 & $1,4,6,10,13,16,17,19,20,21$ \\
\hline 2.2 & Carencia de concientización crítica & 4 & $2,10,18$ \\
\hline 2.3 & Carencia de concientización investigativa & 2 & 10,11 \\
\hline 2.4 & Carencia de concientización empresarial & 1 & 15 \\
\hline
\end{tabular}

Fuente: elaboración propia

En estas ponencias se expone un panorama de la educación contable en el cual no existe conciencia pedagógica por lo social, puesto que "no interesa que el contador en formación conozca la racionalidad del registro, es decir, su explicación causal y sus implicaciones económicas y sociales” (Ordoñez, 2007, p. 37). En efecto, se observa una educación contable que ratifica "dócilmente la demagogia e injusticias que subyacen en el sistema actual". Ante esta situación, la educación contable guía pedagógicamente al estudiante para que permanezca "al margen de una apuesta por la construcción y [el] fortalecimiento de la democracia" (Gallón, 2013, p. 113).

En lo referente a la ausencia de pedagogía crítica en la educación contable, se señala que no se puede dar "la imposición de unos valores establecidos en nombre de una naturaleza en sí de las cosas, pero [eso] tampoco significa que la formación conduzca a un enjuiciamiento de la realidad" (Londoño et al., 2014, p. 148). En consecuencia, debe promoverse una perspectiva crítica que permita analizar los escenarios del saber contable, relacionándolos con todas sus esferas.

Por su parte, la tercera categoría expresa la carencia pedagógica que encierra el desarrollo investigativo. Las ponencias que corresponden a ese ámbito plantean que son escasas las ocasiones que invitan al estudiante a la investigación. Esto ocurre porque la educación contable no le trasmite "espíritu investigativo [a] los estudiantes, [puesto que] no hay interés por ello ni [es algo que] se valora” (Asprilla, 2009, p. 251).

En la última categoría, que versa sobre la falta de concientización empresarial, solamente una referencia hace alusión a las debilidades pedagógicas que respectan a "aspectos de proyección empresarial, asesoramiento y consultoría" (Bernal, 2012, p. 169). La ponencia mencionada enfatiza en el seguimiento que debe realizar la educación contable a los pequeños y medianos emprendedores, especialmente a los dedicados a la actividad agrícola. En consecuencia, ese documento plantea que actualmente existe proyección empresarial en la educación contable, pero esta no va dirigida hacia el primer sector de la economía, sino hacia la economía financiera e industrial.

Comentario: El objetivo común de las ponencias que son clasificadas en este grupo es revelar el problema pedagógico que subyace en la educación contable; un conflicto dado en términos de la indisposición para ofrecer una formación que cuente con un sentido social, crítico, investigativo y empresarial. En suma, para los estudiantes es claro que, por todos los acontecimientos descritos y por su enfoque actual, la educación contable no busca orientar pedagógicamente al estudiante en un ambiente de dudas sociales, críticas, investigativas y empresariales (aspectos correspondientes al primer sector de la economía). Estas debilidades evidencian el ambiente monocompetente al que responde la educación contable; un dominio que no promueve 
un estudio integral de la contabilidad que permita articularla con mejores comprensiones de la desigualdad social y los casos de corrupción que vive el país.

\section{Enseñanza}

TABLA 11

Grupo analítico 3

\begin{tabular}{c|l|c|c}
\hline $\mathbf{N} \cdot{ }^{\circ}$ & \multicolumn{1}{|c|}{ Categoría analítica } & Citas & Ponencias \\
\hline \hline 3.1 & Enseñanza con énfasis instrumental & 12 & $7,12,13,14,16,19,22,23$ \\
\hline 3.2 & Enseñanza con énfasis normativo & 4 & $6,7,10,15$ \\
\hline 3.3 & Enseñanza con énfasis financiero & 2 & 7,14 \\
\hline
\end{tabular}

Fuente: elaboración propia

En la primera categoría, que se dedica a la enseñanza con énfasis instrumental, se clasifican las ponencias que buscan evidenciar los efectos educativos ocasionados por la racionalidad que prevalece en el ambiente ideológico y político del orden social y económico capitalista. Por ejemplo, se plantea que bajo esta concepción "se ha consolidado una visión profusamente pragmática respecto del conocimiento, [de modo que este] es visto únicamente en el sentido utilitario" (Cuevas y Grajales, 2007, p. 66); así, la "enseñanza contable en Colombia se orienta principalmente hacia el ejercicio de la práctica” (Acevedo, 2010, p. 35). En síntesis, se da lugar a una educación "para el adiestramiento desde la transmisión de conocimiento [, una fórmula] impregnada de racionalidad instrumental” (Acevedo, 2010, p. 33).

En tanto, se identifica en la educación contable una eminencia normativa y otra financiera. Por una parte, en la normativa se hace mención a una formación centrada en "aspectos normativos [tributaristas] y de adopción de políticas" (Bernal, 2012, p. 168). Por otra parte, en el caso de lo financiero, se plasma un tipo de enseñanza que "reduce la visión de la Contabilidad hacia un fin netamente financiero" (Acevedo, 2012, p. 145).

Comentario: De acuerdo con los ponentes, en la Contaduría Pública el ambiente de aprendizaje va dirigido hacia un solo sentido, de modo que en la concepción de la educación contable sobresale la eminencia instrumental y funcional. Los estudiantes observan que el énfasis instrumental en la enseñanza contable se complementa con el énfasis normativo y financiero, dando lugar a un aprendizaje limitado y reduccionista. En ese plano y ante esa problemática, el acercamiento transdisciplinar constituye una alternativa viable; sin embargo, a juicio de los estudiantes, en ese contexto resulta complejo generar un diálogo entre disciplinas, máxime cuando la contabilidad solo interviene en la esfera de los negocios.

\section{El sentido de los trabajos de los estudiantes sobre educación contable}

Como se expuso previamente, el propósito de este artículo es auscultar el sentido (Ruíz, 2006) de las ponencias estudiantiles que abordaron problemáticas claves de la educación contable. Con el fin de avanzar hacia tal objetivo, es necesario vincular el marco referencial presentado en los tres primeros acápites con la síntesis temática y los grupos analíticos de los problemas de educación contable correspondientes. En el siguiente acápite se desarrolla tal análisis, como parte de las conclusiones y las consideraciones finales. 


\section{Conclusiones y consideraciones finales}

Entre 1975 y 1990, el gremio estudiantil colombiano se distinguió por fomentar la movilización popular del sector rural, estudiantil y trabajador (Achila, 2012). Tal accionar tuvo el ánimo de rechazar las dinámicas económicas y sociales dominantes, que estaban inmersas en el capitalismo y en los modelos de desarrollo neoliberales. Situándose en este contexto estudiantil, la Fenecop surgió y se estructuró en 1988 (Sarmiento y Muñoz, 2011).

Cabe destacar que los líderes estudiantiles que conformaron la Fenecop se sumaron a las voces de protesta que caracterizaron el ambiente social y político de las décadas de 1980 y 1990 en Colombia. Asimismo, dichos estudiantes se vincularon con la reivindicación social del proceso nacionalista de la Contaduría Pública, que en sus primemos momentos (1930-1960) buscó defender la soberanía nacional, pues “todos los planteamientos nacionales [giraron] en torno a la repartición de mercado; básicamente la lucha se [libró] contra los contadores extranjeros y su autorización para operar en el medio” (Gracia, 1991, p. 199). Con la adhesión de los estudiantes a la causa gremial, se incorporó al proyecto nacionalista una estrategia académica centrada en la investigación (Sarmiento y Muñoz, 2011); filiación que otorgó fortalezas significativas a dicho movimiento social, y que permitió su expansión hacia la esfera académica universitaria.

De acuerdo con lo anterior, se evidencia en este trabajo el importante rol de los estudiantes que fueron ponentes en las comisiones educativas de los últimos catorce congresos nacionales organizados por la Fenecop. Dichos estudiantes han procurado seguir hilando el trabajo académico-político, con miras a problematizar el estado actual de la educación contable y del país. En otras palabras, han continuado con la estrategia investigativa, en tanto que se han propuesto estudiar y buscar soluciones a los problemas sociales y económicos que encierra el saber contable (Rojas, 2009).

Los estudiantes exponen acertadamente diferentes problemáticas de la educación contable, pues ponen en evidencia las falencias de un panorama académico en el que no se contemplan las relaciones comerciales, sociales, ideológicas y políticas subyacentes en el saber contable; sentido en el cual sostienen que la contabilidad (pilar fundamental en la formación contable) no se enseña como un área de investigación e indagación sociohistórica (Gil, 2010; Ospina, 2006). Por el contrario, señalan los educandos, esta se imparte como una ciencia que es percibida como objetiva, neutra y carente de consecuencias sociales (Rojas, 2009).

Así, los estudiantes recurren al estudio de temas en los que — según argumentan — se anclan las principales disfuncionalidades de la educación contable; dichos tópicos son la sociedad, el sujeto, la contabilidad y la Contaduría Pública (ver Figura 1). Con base en esos cuatro referentes, los estudiantes caracterizan elementos fundamentales de la educación y de la sociedad, pero también identifican factores temáticos específicos de la enseñanza contable. De acuerdo con lo anterior, la amplitud de los temas obedece a la extensión de los problemas dados en el contexto de la educación contable; y el número de temas consultados es vasto, porque los problemas educativos tienen una naturaleza holística. En suma, el problema educativo de la Contaduría Pública no se reduce a ser un asunto exclusivo del currículo; según es posible observar con los trabajos de los estudiantes, este se mueve de acuerdo con diferentes temáticas, entre ellas las curriculares o las que tienen que ver con la institución educativa.

También de acuerdo con los estudiantes, la educación contable enfrenta una problemática que se matiza según dos grupos de perspectivas críticas: (a) el conformado por las que se relacionan con el condicionamiento político y económico de la contabilidad (Gil, 2010), y (b) el correspondiente a las originadas como consecuencia de la instrucción de tipo fragmentario, que confina la enseñanza a ocuparse del componente instrumental de la contabilidad (Grajales y Cuevas, 2010). De lo anterior se deriva el carácter nemotécnico del estudio de la materia.

Cabe anotar que el más influyente de los dos horizontes es el primero. En dicho plano temático, los estudiantes destacan los problemas consignados en la categoría que atañe (a) al contexto y el currículo; tópico que ha sido abordado a fondo previamente. Por otra parte, en cuanto respecta al segundo horizonte 
problémico, los estudiantes exponen los aspectos señalados en las categorías que respectan a (b) la enseñanza y (c) la pedagogía.

De acuerdo con los aspectos señalados, en cuanto atañe a la categoría que se dedica (a) al contexto y el currículo, los estudiantes sostienen que los grupos económicos participan activamente en la configuración de la educación contable: factor que debilita de modo notorio los propósitos de formación, aunque fortalezca la mirada funcional del pensamiento contable. Ante ese panorama, los estudiantes padecen condicionamientos que tienen fuertes efectos en la contabilidad, debido al criterio epistemológico de tecnociencia social (Gil, 2010) que la ha limitado como campo del conocimiento. De acuerdo con esa limitación conceptual, resulta natural que la educación contable se vea confinada a las disposiciones legales y económicas del contexto sociohistórico (Gómez, 2010), pues estas otorgan legitimidad y materializan el ejercicio del profesional contable (Cubides, 1991).

De ese modo, la evolución económica y política de Colombia es determinante para recrear la problematización formulada por los estudiantes. Su natural desconcierto no se atribuye exclusivamente al hecho de que la empresa sea considerada el eje fundamental de la educación contable, sino que el problema reside en el fenómeno económico y político que ha permitido la profundización del estado empresarial adentro de un ámbito de gobernanza corporativa. En ese sentido, el malestar estudiantil radica en la acogida acrítica y notoria que tuvieron las políticas de modernización, porque mediante ellas el país instauró el espiritu capitalista y los modelos de desarrollos neoliberales (Catchpowle et al., 2004; Chiapello, 2017; PuelloSocarrás, 2008; Sombart, 1979; Weber, 2009). De acuerdo con ese contexto de individuación, la educación contable es diseñada con fines de lucro y es puesta al servicio de los intereses políticos y empresariales (Boyce, 2008; Cruz, 1998, 2016).

En lo que respecta a las categorías que se concentran en (b) la enseñanza y (c) la pedagogía, los estudiantes exploran cómo en la educación contable se privilegia la enseñanza que tiene énfasis instrumental, y la pedagogía que carece de un sentido social. Estas observaciones se instalan en un horizonte problemático en el cual el ejercicio educativo se reduce a la instrucción financiarizada, ${ }^{7}$ que solamente prioriza el componente instrumental de lo contable (Bento et al., 2017; Grajales y Cuevas, 2010). En el sentido descrito, la recreación de estos problemas guarda estrecha relación con el primer horizonte problémico que se expuso; aquel fenómeno político y económico, que ha caracterizado el ambiente educativo funcionalista de la Contaduría Pública en Colombia, caracteriza también el panorama educativo funcionalista de otras profesiones y otros saberes.

Aclarado lo anterior, es importante señalar que, acorde con los estudiantes, difícilmente se podría hablar de una pedagogía con sentido social y de una enseñanza contable desligada de su carácter instrumental. Lo anterior obedece a que las condiciones sociales vividas en el país durante el ingreso a la modernidad (Méndez, 1988; Cruz, 1998, 2016) provocaron una ruptura histórica de tipo mental y cultural que profundizó la funcionalidad acrítica en las actividades sociales.

En consecuencia, la educación contable se ve en la tarea de alentar la instrucción memorística y tradicional de tipo empresarial (Sarmiento y Muñoz, 2011). Sin embargo, tal resultado obedece además a que culturalmente esta no ha fundado sus bases en el proyecto moderno, el cual busca movilizar una revolución ideológica que dé paso a la búsqueda epistémica, estética y ética que permitiría comprender el complejo universo de representaciones sociales y humanas que se presentan en tal contexto (Cruz, 1998, 2016).

Como se puede apreciar, el problema educativo del saber contable ha sido analizado por la comunidad estudiantil mediante la agrupación de los aspectos concernientes en diversos temas, sin que estos sean mutuamente excluyentes; al contrario, dicha diversidad muestra el desarrollo del pensamiento contable en Colombia alrededor de las cuestiones educativas. En ese sentido, los problemas identificados denuncian múltiples factores; sin embargo, tienen cuatro puntos de encuentro: el contexto, el currículo, la enseñanza y la pedagogía. 
Gracias al análisis de contenido aplicado, se nota que los problemas de la educación contable son resultado de una preocupación principalmente social, formativa, disciplinal y profesional de la contabilidad (ver Figura 2). Mediante estos hallazgos es posible entender que, para interrumpir el afianzamiento problemático de la Contaduría Pública, el cambio educativo sustancial pertinente debe considerar asimismo el llamado a pensar la sociedad, el saber contable - tanto la disciplina como la profesión-y el campo formativo de los sujetos.

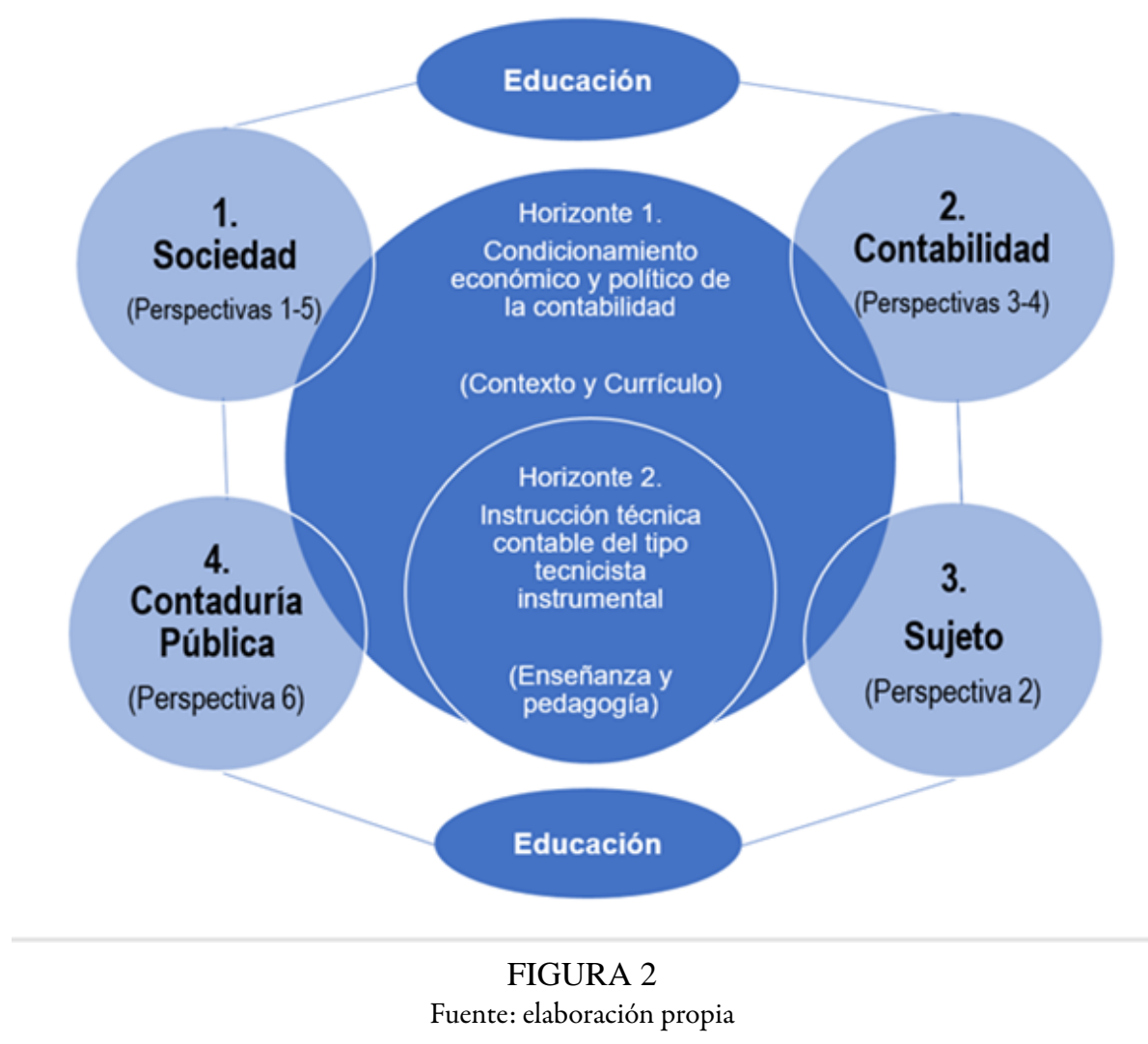

\section{Epílogo: el diálogo y la formación individual y colectiva}

La actividad investigativa que adelanta el gremio estudiantil se ha desarrollado gracias a un proceso riguroso de lectura y escritura que asumieron los estudiantes desde la década de 1980; una iniciativa que comenzó con los objetivos de analizar el campo de la educación contable y de buscar soluciones a las inconsistencias que se manifestaban desde ese momento. En consecuencia, las intervenciones estudiantiles, que se manifestaron mediante sus ponencias, han permitido construir un legado reflexivo y crítico del mundo, del país, de la educación, de la contabilidad, del ejercicio contable, de los individuos y del pensamiento. Es así como, desde hace más de cuatro décadas, estas dinámicas estudiantiles han auspiciado el diálogo y la formación tanto en la dimensión individual como en la colectiva.

De manera autónoma y autogestionada, ${ }^{8}$ el gremio estudiantil ha consolidado un aporte significativo para la tradición investigativa que ha buscado interrogar las prácticas educativas del saber contable. En otras palabras, desde adentro de la reivindicación, los estudiantes han construido pensamientos y afectos propicios para entender y proyectar la realidad social de la educación contable colombiana.

Difícilmente el proceso académico de problematización adelantado por los estudiantes suscitará por sí solo un giro al panorama desalentador de la educación contable. Sin embargo, este artículo permite sostener que una parte fundamental del movimiento que ahora representa reformas curriculares y cambios positivos para la educación contable es liderado por profesores e investigadores que otrora intervinieron en la Fenecop. Lo 
anterior indica que el diálogo y la formación, dada tanto en la esfera de lo individual como en la de lo colectivo, obtiene resultados de largo plazo.

En consecuencia, se pude afirmar que el proceso investigativo estudiantil no resuelve de facto el problema educativo; más bien, constituye una apuesta formativa que invita a creer en la búsqueda de una dimensión ética y estética que comprenda en igual medida lo grupal y lo individual. Una iniciativa idónea para entender la complejidad del orden social; un accionar que influirá de forma determinante en los próximos cambios educativos del saber contable.

\section{Agradecimientos}

Este artículo se deriva del trabajo de grado Analitica y desarrollos de la educación contable: pensamiento estudiantil-Fenecop-años 2000-2014, el cual fue sustentado y presentado para optar al título de contador público. El autor agradece a los profesores William Rojas, Gregorio Giraldo y Jhonny Grajales. Además, extiende su gratitud a Eliana Franco, Victoria Rodríguez, Alejandro Sánchez, Rita Martínez y Santiago Moreno por los aportes que hicieron a las ideas aquí consignadas. Un apoyo como el de ellos es francamente indispensable para seguir caminando en tiempos de adversidad y desilusión. Finalmente, el autor desea expresar sus agradecimientos a los evaluadores anónimos del artículo.

\section{Referencias}

Acevedo, J. (2010). Una aproximación a la actualidad de la educación contable desde la óptica de la ideología dominante. En Ponencias, XXII Congreso Nacional de Estudiantes de Contaduría Pública (pp. 24-35). Santa Marta: Fenecop-Zatsiji.

Acevedo, J. (2012). La necesidad de la literatura y las ciencias sociales en la formación del estudiante de Contaduría Pública. En Ponencias, XXIII Congreso Nacional de Estudiantes de Contaduría Pública (pp. 131-148). Barranquilla: Fenecop-Unica-Geicuc-Universidad del Atlántico-Corporación Universitaria de la Costa.

Achila, M. (2012). El movimiento estudiantil en Colombia, una mirada histórica. Revista del Observatorio Social de América Latina, 13(31), 71-97.

Acosta, S. (2015). El componente público de la contaduría pública: urgencia de la formación al respecto de un elemento necesario para la transformación social. En Ponencias, XXVI Congreso Nacional de Estudiantes de Contaduría Pública (pp. 99-114). Florencia: Fenecop-Cecam-Universidad de la Amazonia.

Asprilla, F. (2009). Administración y desarrollo del pensamiento contable. En Ponencias, XXI Congreso Nacional de Estudiantes de Contaduría Pública (pp. 239-252). Armenia: Fenecop-Coesco-Universidad del Quindío.

Beltrán, L. (2001). Memoria histórica de Contaduría Pública en la Facultad de Ciencias Económicas. En A. Hernández y B. Herrera (eds.), Búsquedas y logros desde la academia. 50 años Facultad de Ciencias Económicas, Sede Bogotá (pp. 408-413). Bogotá: Universidad Nacional de Colombia.

Bento, R., Mertins, L.y White, L. (2017). Ideology and the balanced scorecard: An empirical exploration of the tension between shareholder value maximization and corporate social responsibility. Journal of Business Ethics, 142(4), 769-789.

Bernal, H. (2012). Cambio paradigmático en dos conceptos globalizados del nuevo contador público. En Ponencias, XXIII Congreso Nacional de Estudiantes de Contaduria Pública (pp. 151-169). Barranquilla: Fenecop-UnicaGeicuc-Universidad del Atlántico-Corporación Universitaria de la Costa.

Boyce, G. (2008). The social relevance of ethics education in a global(ising) era: From individual dilemmas to systemic crises. Critical Perspectives on Accounting, 19(2), 255-290.

Catchpowle, L., Cooper, C. y Wright, A. (2004). Capitalism, states and ac-counting. Critical Perspectives on Accounting, 15(8), 1037-1058. 
Caracol Radio. (27 de marzo de 2015). La minería a cielo abierto no es rentable en Colombia. Caracol Radio. Recuperado de http://www.caracol.com.co/noticias/regionales/la-mineria-a-cielo-abierto-no-es-rentable-en-c olombia/20141221/nota/2560129.aspx

Córdoba, J. (2014). Ficha biográfica: Pedro Nel Ospina. Bogotá: Banco de la República. Recuperado de http://www. banrepcultural.org/blaavirtual/biografias/ospipedr.htm

Chiapello, E. (2017). Critical accounting research and neoliberalism. Critical Perspectives on Accounting, 43(Supplement C), 47-64.

Cruz, F. (1998). Cultura de la modernidad y crisis social. En La sombrilla planetaria. Modernidad y postmodernidad en la cultura (pp. 9-24). Bogotá: Planeta Colombiana Editorial.

Cruz, F. (2016). Doce interrogantes sobre modernidad y postmodernidad. En La sombrilla planetaria. Modernidady postmodernidad en la cultura (pp. 25-47). Medellín: Sílaba Editores.

Cuevas, J. (2008). La empresa como demiurgo de la educación del profesional de la Contaduría Pública. En Ponencias, XX Congreso Nacional de Estudiantes de Contaduría Pública (pp. 27-46). Cali: Fenecop-Asecuva-Universidad del Valle.

Cuevas, J. y Grajales, J. (2007). El pensamiento único y su relación con la formación del estudiante de Contaduría Pública en el área de teoría contable. En Ponencias, XIX Congreso Nacional de Estudiantes de Contaduría Pública (pp. 52-67). Medellín: Fenecop-Gecua-Universidad de Antioquia.

Daza, H. (2010). La educación contable alternativa: entre la urgencia del adiestramiento instrumental y la emergencia de la formación disciplinal. En Ponencias, XXII Congreso Nacional de Estudiantes de Contaduría Pública (pp. 41-64). Santa Marta: Fenecop-Zatsiji.

Duque, D. (2002). Medios y fines de la educación contable: una mirada culturalista. En Ponencias, XVI Congreso Nacional de Estudiantes de Contaduría Pública (pp. 54-70). Manizales: Fenecop-Cicum-Universidad de Manizales.

Gallón, N. (2013). La formación ciudadana en el contador público: una apuesta ineludible desde la educación filosófica y democrática. En Ponencias, XXIV Congreso Nacional de Estudiantes de Contaduría Pública (pp. 105-119). Medellín: Fenecop-Yupana-Politécnico Colombiano Jaime Isaza Cadavid.

García, M. (2009). Problemas éticos del contador público y su relevancia social. En Ponencias, XXI Congreso Nacional de Estudiantes de Contaduria Pública (pp. 216-235). Armenia: Fenecop-Coesco-Universidad del Quindío.

Gil, J. (2010). Retos de la contabilidad frente a la globalización: perspectivas de la teoría y la investigación contable. En C. Barrios y W. Rojas (comp.), Conjunciones y disertaciones:pensando la contabilidad en el siglo xxi (pp. 101-126). Cali: Pontificia Universidad Javeriana Cali-Universidad del Valle.

Gómez, C. y Muñoz, C. (2001). La formación integral en Contaduría Pública: elemento fundamental para la construcción de un nuevo país. En Ponencias, XV Congreso Nacional de Estudiantes de Contaduría Pública (pp. 148-166). Cali: Fenecop-Asecuva-Universidad del Valle.

Gómez, J. (2003). Elementos conceptuales para una propuesta pedagógica en la formación ética del estudiante de Contaduría Pública. En Ponencias, XVII Congreso Nacional de Estudiantes de Contaduría Pública (pp. 145-168). Popayán: Fenecop-Gicuc-Universidad del Cauca.

Gómez, M. (2016). NIIF y MIPYMES: retos de la contabilidad para el contexto y la productividad. Cuadernos de Administración, 29(53), 49-76.

Gómez, M. (2010). Interés público y ejercicio de la contaduría pública: miradas al contexto internacional y aprendizaje para la profesión en Colombia. Revista Unimar, 28(2), 77-90.

Gómez, M. y Ospina, C. (2009). Ampliando las fronteras en la disciplina contable: una introducción para la contextualización de los ejemplares heterodoxos. En M. Gómez y C. Ospina (eds.), Avances interdisciplinarios para una comprensión crítica de la contabilidad. Textos paradigmáticos de las corrientes heterodoxas (pp. 13-35). Bogotá: Escuela de Administración y Contaduría Pública, Universidad Nacional de Colombia-Departamento de Ciencias Contables, Universidad de Antioquia. 
Gracia, E. (1991). Las transnacionales auditoras. Aproximación al entendimiento de su naturaleza. En H. Cubides (ed.), Historia de la Contaduría Pública en Colombia Siglo XX. Elementos para su interpretación (pp. 139-238). Bogotá: Fundación Universidad Central.

Grajales, J. y Cuevas, J. (2010). La importancia de la formación del estudiante de contaduría pública en el área de teoría contable. El caso de la Universidad del Valle. Revista Contaduría Universidad de Antioquia, (57), 83-105.

Gutiérrez, F. (2005). Evolución histórica de la contabilidad de costes y gestión (1885-2005). Revista Española de Historia de la Contabilidad, 2(2), 100-122.

Hernández, D. (2003). Integración del conocimiento: observatorio de la realidad posmoderna. Una mirada a la disciplina contable. En Ponencias, XVII Congreso Nacional de Estudiantes de Contaduría Pública (pp. 126-140). Popayán: Fenecop-Gicuc-Universidad del Cauca.

Londoño, D., López, D. y Moreno, C. (2014). La contabilidad y las teorías de la argumentación: una taxonomía para el devenir formativo. En Ponencias, XXV Congreso Nacional de Estudiantes de Contaduría Pública (pp. 145-167). San José de Cúcuta: Fenecop-Asecop-Universidad Francisco de Paula Santander.

Méndez, R. (1988). Formación del capitalismo en Colombia. Bogotá: Grijalbo.

Millán, R. (1975). Historia de la Contaduría Pública en Colombia. Bogotá: Editorial Retina.

Ospina, C. (2006). Las tramas de la contabilidad: trazos para quienes empiezan su formación en Contaduría Pública. Revista Contaduria Universidad de Antioquia, (48), 155-186.

Ordoñez, S. (2007). El énfasis de lo disciplinar sobre lo profesional para la formación del contador público: una experiencia en formación contable. En Ponencias, XIX Congreso Nacional de Estudiantes de Contaduría Pública (pp. 33-47). Medellín: Fenecop-Gecua-Universidad de Antioquia.

Pineda, J. y Calderón, C. (2004). Intereses subyacentes de la propuesta de estandarización de la educación contable. En Ponencias, XVIII Congreso Nacional de Estudiantes de Contaduría Pública (pp. 124-142). Bogotá: FenecopNosotros-Universidad Nacional de Colombia.

Polo, W. (2009). Características del currículum en la educación del profesional de la Contaduría Pública. En Ponencias, XXI Congreso Nacional de Estudiantes de Contaduria Pública (pp. 198-211). Armenia: Fenecop-CoescoUniversidad del Quindío.

Puello-Socarrás, J. (2008). Nueva gramática del neo-liberalismo. Itinerarios teóricos, trayectorias intelectuales, claves ideológicas. Bogotá: Universidad Nacional de Colombia.

Restrepo, L. y Rodríguez, M. (2016). Educación en contabilidad ambiental. Una aproximación desde el pensamiento ambiental. En Ponencias, XXVII Congreso Nacional de Estudiantes de Contaduría Pública (pp. 113-128). Medellín: Fenecop-Gecua-Universidad de Antioquia.

Rodelo, M. y Chamorro, C. (2016). Pensamiento crítico como elemento fundamental en la formación contable y referente pedagógico en el marco del proceso de paz. En Ponencias, XXVII Congreso Nacional de Estudiantes de Contaduría Pública (pp. 91-110). Medellín: Fenecop-Gecua-Universidad de Antioquia.

Rodríguez, M. (2016). El senti-pensar latinoamericano: una apuesta por el pensamiento crítico de la formacióneducación en contabilidad. En Ponencias, XXVII Congreso Nacional de Estudiantes de Contaduría Pública (pp. 131-144). Medellín: Fenecop-Gecua-Universidad de Antioquia.

Rojas, W. (ed.). (2001). Pensamiento contable. Memorias de los congresos estudiantiles 1984-2000. Cali: FenecopUniversidad del Valle.

Rojas, W. (2009). Congoja por una educación contable fútil. En Irrupciones significativas para pensar la contabilidad (pp. 193-207). Cali: Universidad del Valle.

Rueda, G. (2010). Contabilidad para la dignidad social. Los aportes de la teoría crítica para la construcción de una nueva dimensión internacional para la contabilidad. Contaduría Universidad de Antioquia, (57), 203-219.

Ruíz, A. (2006). Texto, testimonio y metatexto. El análisis de contenido en la investigación en educación. En A. Jiménez y A. Torres (comp.), La práctica investigativa en ciencias sociales (pp. 45-59). Recuperado de http://bibliotecavi rtual.clacso.org.ar/ar/libros/colombia/dcsupn/practica.pdf 
Sandoval, J. (2005). Movimiento universitario por los derechos humanos. En O. Vargas (ed.), Movimientos Universitarios. América Latina siglo XX (pp. 97-105). Tunja: Red de Universidades de Colombia.

Santos, E. (2017). La misión Kemmerer. Bogotá: Banco de la República. Recuperado de http://www.banrepcultural. org/blaavirtual/revistas/credencial/abril2005/mision.htm

Sarmiento, H. y Muñoz, S. (2011). Banderas en alto. Una Arqueología del Proceso de Nacionalización de la Contaduria Pública en Colombia. Medellín: Politécnico Jaime Isaza Cadavid.

Sombart, W. (1979). Lujo y capitalismo. Madrid: Alianza Editorial.

Sunder, S. (2005). Teoría de la contabilidad y el control. Bogotá: Facultad de Ciencias Económicas, Universidad Nacional de Colombia.

Torres, S. y Usma, L. (2015). Perspectivas de la educación contable. Desafíos para el reconocimiento de los espacios socio-ambientales en los programas de Contaduría Pública en Colombia. En Ponencias, XXVI Congreso Nacional de Estudiantes de Contaduría Pública (pp. 85-95). Florencia: Fenecop-Cecam-Universidad de la Amazonía.

Weber, M. (2009). La ética protestante y el "espiritu del capitalismo". Madrid: Alianza Editorial.

Zeff, S. (2003). How the U.S. accounting profession got where it is today: Part II. Accounting Horizons, 17(4), 267-286.

\section{Notas}

1 Todos los congresos nacionales son organizados por grupos estudiantiles de un programa académico y/o facultad de Contaduría Pública del país (por ejemplo, Coesco de la Universidad del Quindío, o Nosotros de la Universidad Nacional de Colombia), de acuerdo con la estructura de la Fenecop. Sin embargo, con el ánimo de agrupar en dicha federación a todas las colectividades que han contribuido a la realización de los congresos, en adelante se insistirá en que los congresos nacionales son gestados por la Fenecop.

2 Tomado del libro de ponencias del "XXVII Congreso Nacional de Estudiantes de Contaduría Pública y VII Congreso Latinoamericano de Estudiantes de la Disciplina Contable”, que fue organizado por el Grupo de Estudiantes de Contaduría de la Universidad de Antioquia (Gecua) en el año 2016. Los estatutos generales contenidos en este libro de ponencias tienen incorporada la última reforma estatutaria efectuada en la "XIII Asamblea Nacional de Delegados" (AND), que fue dictaminada en el año 2008, en Barranquilla.

3 Cabe precisar que en el periodo de revisión — que se extiende desde el año 2000 hasta el 2016 —, a lo largo de las ediciones XIX, XXIII y XXVII de los congresos, los grupos estudiantiles encargados de organizar dicho encuentro cambiaron la dinámica del trabajo, que pasó transitoriamente de estar organizado en comisiones a implementar otra perspectiva basada en núcleos problémicos. Aclarado lo anterior, se añade que en este artículo se hablará de comisiones, por ser la dinámica más utilizada en los congresos.

4 Se toma dicho antecedente como punto de partida cronológico, pues las ponencias revisadas en el presente estudio son las publicadas del año 2000 en adelante. A diferencia de la investigación que adelantó Rojas (2001), en este artículo solo se analizan los trabajos presentados en la comisión educativa.

5 La Contaduría Pública comenzó a dictarse como un programa universitario en el año 1952, cuando los decretos 356 de 1951 y 686 de 1952 reglamentaron sus estudios "en el ámbito de la enseñanza universitaria de comercio, creando la Facultad Nacional de Contaduría y Ciencias Económicas” (Beltrán, 2001, p. 408). En concordancia, la contabilidad que es enseñada en el campo universitario debería reflejar un carácter disciplinal propio de un área del conocimiento universal.

6 Se cuentan catorce congresos nacionales, desde la versión XIV (2000) hasta la XXVII (2016).

$7 \quad$ Para Gómez (2016), la financiarización puede se entendida como la etapa actual de la globalización, en la cual la gestión organizacional y el gobierno de la empresa se centran en conseguir la maximización del valor. Así, expone Gómez (2016), citando a Giraldo (2005), que la "Financiarización significa que, en el proceso económico, la lógica financiera se sobrepone a la lógica productiva” (pp. 57-58).

8 Las actividades que realizan los grupos de base y la Fenecop son financiadas mayoritariamente con recursos propios de la organización estudiantil.

* Artículo de revisión.

\section{Licencia Creative Commons CC BY 4.0}

Para citar este artículo: Ramírez Henao, D. F. (2017). Análisis y desarrollo de la educación contable: temáticas de su abordaje y principales problemáticas según el pensamiento estudiantil propuesto por la Fenecop (2000-2016). Cuadernos de Contabilidad, 18(46). 1-28. https://doi.org/10.11144/ Javeriana.cc18-46.adec 